\title{
Sooting Tendencies of Diesel Fuels, Jet Fuels, and Their Surrogates in Diffusion Flames
}

\author{
Dhrubajyoti D. Das ${ }^{\mathrm{a}, *}$, Charles S. McEnally ${ }^{\mathrm{a}}$, Thomas A. Kwan ${ }^{\mathrm{a}}$, Julie B. Zimmerman ${ }^{\mathrm{a}, \mathrm{d}}$, \\ William J. Cannella ${ }^{\mathrm{b}}$, Charles J. Mueller ${ }^{\mathrm{c}}$, Lisa D. Pfefferle ${ }^{\mathrm{a}}$ \\ ${ }^{a}$ Yale University, Dept. of Chemical and Environmental Engineering, 9 Hillhouse Ave, New Haven, CT 06520 \\ ${ }^{b}$ Chevron Energy Technology Co., a division of Chevron USA, Richmond, CA 94802 \\ ${ }^{c}$ Sandia National Laboratories, 7011 East Avenue, Livermore, CA 94550 \\ ${ }^{d}$ Yale University, School of Forestry and Environmental Studies, 195 Prospect St, New Haven, CT 06520
}

\begin{abstract}
Surrogates of transportation fuels are useful design tools for developing engines with cleaner and more efficient combustion. It is important that information about the sooting tendency of the target fuel be incorporated in the formulation of these surrogates. Toward that end, in this work we report experimentally measured sooting tendencies of several diesel and jet fuels, surrogates of these fuels, and pure compounds which are components of these surrogates. These fuels, surrogates, and compounds were separately doped in trace quantities ( $0.5 \%$ by mass) into the fuel of a methane-air laminar coflow flame. The sooting tendencies, expressed as Yield Sooting Indices (YSIs), were quantified from spatially resolved two-dimensional soot volume fraction distributions of these flames as measured with color ratio pyrometry. Previous means of matching the sooting behavior of the surrogate to the fuel, such as by matching the fuel's hydrogen content or its double bond equivalent, were found to be inadequate because these approaches don't fully account for the effects on the fuel's sooting tendency of branching in aliphatics and alkyl substitutions in aromatics. A strong correlation was observed between the YSI and the relative abundance of different types of carbon atoms (as quantified by ${ }^{1} \mathrm{H}$ and ${ }^{13} \mathrm{C}$ NMR spectroscopy) in these fuels and compounds, indicating that such NMR characterization can capture essential structure-specific sooting information of relevance to surrogate formulation. Based on these YSI measurements, we demonstrate two approaches to predict the sooting tendency of a fuel surrogate. These approaches, based on (1) the choice of pure compounds that are blended to create a surrogate, or (2) the distribution of carbon atom types in a surrogate, can be used to tune the surrogate's formulation to match the sooting tendency of its target fuel.

Keywords: YSI; soot volume fractions; diesel surrogate; jet fuel surrogate; NMR fuel characterization
\end{abstract}

\footnotetext{
${ }^{*}$ Corresponding author

Email address: dhrubajyoti.das@yale.edu (Dhrubajyoti D. Das)
}

(C) 2017. This manuscript version is made available under the Elsevier user license http://www.elsevier.com/open-access/userlicense/1.0/ 


\section{Introduction}

Carbonaceous particulate matter emissions from diesel engines, also known as soot, have a significant impact on human health and the global climate. According to the World Health Organization [1], particulate matter $\left(\mathrm{PM}_{2.5}\right)$ air pollution is a leading cause of mortality worldwide, contributing to over 800,000 premature deaths per year. Human and laboratory studies suggest that soot is a likely carcinogen [2,3], and exposure to soot poses the greatest risk of cancer of all air pollutants [4]; primary exposure pathways include breathing in air containing soot, either from direct engine exhaust or from its presence in the atmosphere. In addition to harming human health, soot contributes directly to global warming by absorbing sunlight and heating the atmosphere; recent studies indicate that it is the second most important source of climate change, with a radiative forcing only one-third less than $\mathrm{CO}_{2}$ [5]. Finally, soot also effectively impedes advances in automotive fuel economy because combustion strategies that improve efficiency, such as gasoline direct injection (GDI) and compression ignition (CI; i.e., diesel engines), tend to increase emissions [6]. Fortunately, soot emissions from diesel exhaust have a relatively short persistence in the atmosphere ( $\sim 1$ week [5]), and its anthropogenic nature provides society with a strong control mechanism over its emission. Stakeholders are earnestly pursuing approaches for reducing soot emissions, as the expected benefits would be realized in a forseeable timeframe [7].

A sustainable approach to realize this reduction is the development and use of a cleaner combustion system. In principle, automotive engineers can use computer simulations to design engines that optimize the tradeoffs between high fuel efficiency and low emissions. However, petroleum-derived fuels, such as diesel, happen to be chemically complex mixtures containing thousands of hydrocarbons $[8,9]$, which makes computational studies of their fundamental combustion properties intractable. Thus, simplified "surrogate fuels" are useful for representing current transportation fuels [10]. A surrogate fuel is a mixture of a small number of pure compounds whose behavior matches certain characteristics of a target fuel containing many compounds, such as a market diesel fuel. Diesel fuels are an important target fuel for surrogates because diesel engines are a major source of soot emissions [3]. The U.S. military's adoption of the single fuel forward policy [11] mandates using kerosene-based jet fuels in CI engines in ground vehicles for logistical reasons; aviation fuels such as JP-8 are an additional real-world use case of fuels in CI engines, thereby making them important target fuels for surrogate development. Development of surrogates for these fuels has been an area of active research in the recent past, and several extensive reviews of these efforts are available in the literature. The reader is referred to reviews by Dagaut and Cathonnet [12] and Colket et al. [13] for an overview of work done prior to 2007 to develop jet fuel surrogates, and by Farrell et al. [14] and Pitz and Mueller [10] for an outline on the progress made until 2011 in developing diesel surrogate fuels.

Surrogates are traditionally formulated by mixing components in order to mimic some desired physical and/or chemical properties of the target fuel in a heirarchical fashion. Physical fuel properties of interest frequently include density, viscosity, volatility parameters such as boiling/freezing temperature and distillation curve, surface tension, diffusion coefficient, thermal conductivity, specific heat 
capacity, etc. Chemical properties of interest are typically $\mathrm{C} / \mathrm{H} / \mathrm{O}$ content, average molecular weight, heat release rate and total heat release, adiabatic flame temperature, fuel ignition timing and quality, and fuel sooting tendency [15]. Most surrogates in the literature are formulated to match a spectrum of these physical and chemical target fuel properties by matching some measure of the overall chemical composition of the target fuel. Several analytical spectroscopic techniques have emerged recently which provide highly detailed fuel characterization information, allowing researchers to develop surrogates with good compositional fidelity to the target fuel. Such techniques include GC-FIMS (gas chromatography with field ionization mass spectrometry) with PIONA (paraffins, iso-paraffins, olefins, naphthenes, and aromatics), GC $\times$ GC-FID (two-dimensional gas chromatography with flame ionization detection), and ${ }^{1} \mathrm{H}$ and ${ }^{13} \mathrm{C}$ NMR (nuclear magnetic resonance) spectroscopy. The gas chromatography techniques quantify mass fractions of each constituent compound as well as different hydrocarbon classes in the fuel. NMR spectroscopy analyses the fuel at the sub-molecular level by classifying the carbon atoms present in the fuel into distinct types based on the nature of the bonds connecting the atoms, and quantifies the mole fraction of each of these types in the fuel. These techniques have been used in the literature to characterize several gasoline [16], jet [17], and diesel fuels $[18,19]$, as well as guide the development of surrogates for these fuels.

Matching fuel sooting tendency has typically not been a major focus of work on surrogate formulation (and indeed, the sooting behavior of the target fuel was not one of the explicit property targets in [19]). However there are a few works in the literature [20-25] which either explicitly consider the sooting behavior of the target fuel in the formulation of the surrogate, or experimentally compare the sooting behavior of the fuel and its surrogate.

The six-component surrogate developed by Violi et al. [20] (see Table 4 for composition) for a generic JP-8 fuel was one of the first to emulate the sooting tendency, among other physical and chemical properties, of the target fuel. In a related work, Eddings et al. [21] developed a six-component JP-8 surrogate designed to study pool fires. The components ( $n$-octane, $n$-dodecane, $n$-hexadecane, xylenes, decalin, and tetralin) were blended in order to match both the boiling point distribution and smoke point of the target fuel. Lemaire et al. [22] developed one of the first surrogates for a commercial low-sulfur diesel fuel which took the sooting tendency of the fuel into account. The diesel fuel and its two surrogates (binary mixtures of $n$-dodecane and 1-methylnaphthalene), were studied in a turbulent diffusion flame; soot loads were quantified with Laser-Induced Incandescence (LII) and Fluorescence (LIF). Sooting tendency was quantified using the Threshold Sooting Index (TSI). One of the two surrogates, which was formulated to match the TSI of the target fuel, produced similar amounts of soot in the flame as the diesel fuel, though differences were observed in the compositions of species on the surfaces of the soot particles collected from the diesel and surrogate flames. Mensch et al. [23] developed surrogates for an aviation fuel, JP-8, by replicating the fuel's H/C ratio, autoignition characteristics, and sooting tendency. The surrogate was a ternary mixture of two alkanes and a substituted aromatic hydrocarbon (Table 4) chosen to match the TSI of the JP-8 fuel and the surrogate. Dooley et al. [24] also utilized the TSI, along with the average fuel molecular weight, H/C ratio, and 
derived cetane number, as targets to match a 4-component surrogate to a target Jet-A fuel, POSF 4658. The components of the surrogate (Table 4) were blended in proportions which minimized the difference between the aforementioned targets for the fuel and surrogate. The performance of the surrogate was compared to the fuel in several controlled combustion experiments, including a wick-fed laminar diffusion flame, which was used to measure the smoke points of the fuel and surrogate. Additionally, soot volume fractions in the flame were quantified using laser extinction; the peak $f_{v}$ values were found to be comparable for the fuel and the surrogate at their respective smoke points. Witkowski et al. [25] studied three real fuels (gasoline, jet fuel, diesel), two alkanes, and several "simple" surrogate fuels by seeding them in low concentrations ( $2200 \mathrm{ppm})$ in a methane/air nonpremixed flame. The surrogates were binary or ternary mixtures of one or more alkanes (either $n$-heptane, iso-octane, $n$-decane, or $n$-tetradecane) and toluene. Fuel and surrogate sooting tendencies were quantified from $2 \mathrm{D}$ soot $f_{v}$ maps obtained using laser induced incandescence and laser extinction. Soot loads were found to match between some target fuels and their surrogates.

Most surrogate formulation work involving soot has been for jet fuels and jet fuel applications. Many of the components utilized in these jet fuel surrogates fall in the front end of the diesel carbon number range (which is approximately $\mathrm{C}_{10}-\mathrm{C}_{22}$ ). Corresponding surrogate literature on diesel fuels focusing on soot is very sparse [14]. There are several practical reasons for this scarcity. It is typically difficult to carry out experimental measurements with fuel components of such low volatility in the diesel boiling range in traditional smoke point apparatus [23]. Experimental apparatuses which rely on extensive preheating through high-temperature operation to vaporize these fuels risk thermal degradation of the fuel. Additionally, only a relatively small number of the diesel distillation range hydrocarbons (e.g., iso-paraffins and cyclo-paraffins) are available commercially at high purity.

To address these concerns, we have developed an experimental approach, utilizing a fuel doping strategy in a methane/air coflow flame, which allows us to study the sooting behavior of low volatility fuels and compounds. In this approach, we add small amounts of the fuel or compound of interest (dopant) to a lightly sooting base flame and measure the resulting increases in soot concentration. The experimentally measured soot concentrations (expressed as $F_{v \text {, max }}$, defined in $\$ 3.2$ below) are then converted into apparatus-independent Yield Sooting Indices (YSIs) by the normalization equation:

$$
\mathrm{YSI}=A \times F_{v, \max }+B
$$

where $A$ and $B$ are apparatus-specific parameters chosen such that the YSI of $n$-hexane $=0$, and the YSI of benzene $=100$. The primary advantage of this method is that the additive concentrations $-0.5 \%$ by mass in the fuel - are too small to affect the soot concentrations through indirect mechanisms such as dilution of the base fuel or changes in the flame temperature; measured sooting tendencies depend principally on the direct chemical effects of the dopant. Other advantages of this technique include the small dopant sample volume needed for this technique $(\sim 100 \mu \mathrm{L})$, which is two orders of magnitude lower than the minimum sample volume necessary to measure the smoke point of fuels with the ASTM-D1322 method [26]. Because 99.5\% of the fuel is the same for all the doped flames, soot loads 
for all dopants (fuels, surrogates, pure compounds) are measured in identical reactive environments, instead of at the smoke point, which occurs at different flame conditions for different fuels.

The doped flame approach used in this work has been used successfully to experimentally and computationally study the sooting effects of many fuels and pure compounds by our group and others in the literature [25, 27-31]. In a related recent work [32], we demonstrated the feasibility of this approach for studying three high molecular weight/low volatility hydrocarbons which are components of a recent diesel surrogate [19]. In this work, we are extending the experimental approach in [32] to include novel measurements of the YSI of two reference diesel fuels, four reference jet fuels, four diesel surrogates, five jet fuel surrogates, and the components of these surrogates. These fuels and surrogates are listed in Tables 2, 3, and 4. CFA is a certification ultra-low sulfur diesel fuel that is manufactured by Chevron-Phillips Chemical Co. FD9A is a reference diesel fuel developed under the auspices of the Coordinating Research Council [33] to study the effects of fuel-property variations on diesel combustion in engines. POSF 4658 is a composite Jet-A fluid prepared by mixing five individual batches of Jet-A from different U.S. manufacturers. POSF 10264, 10289, 10325 are reference JP-8, Jet-A, and JP-5 fuels respectively, developed under the auspices of the National Jet Fuels Combustion Program [34], and designed to span a range of combustion-related properties, such as flash point, viscosity, and aromatics content. The four diesel surrogates, VOA, VOB, v1, v2, were developed by Mueller et al. [19], and feature increasing levels of compositional accuracy relative to the single target diesel fuel, CFA, upon which they are based. The jet fuel surrogates include formulations featuring 2-6 pure components by Violi et al. [20] ("Sur_1"), Agosta et al. [35], Bruno and Smith [36] ("Modified Aachen", with 1,3,5-trimethylbenzene substituted for 1,2,4-trimethylbenzene), Mensch et al. [23] ("JP-8 surrogate (22)"), and Dooley et al. [24]. These surrogates were formulated to variously match fuel properties such as volatility, boiling point curves, smoke point, advanced distillation curves, average molecular weight, $\mathrm{H} / \mathrm{C}$ ratio, derived cetane number, and threshold sooting index. Apart from the "Modified Aachen" surrogate, none of the surrogate formulations have been altered in the preparation of samples for use in this work. The components of these surrogates comprise a set of 25 unique hydrocarbons in total, listed in Table 1.

The objectives of this study are:

1. To demonstrate the feasibility of YSI as a relevant measure of sooting tendency for real fuels and their surrogates, as well as pure compounds.

2. To characterize the sooting tendency (in terms of YSI) for a set of reference diesel and jet fuels, and recently developed fuel surrogates.

3. To generate a consistent set of experimentally determined benchmark YSI data for compounds commonly considered for developing and validating surrogate mixtures for diesel and jet fuels.

4. To develop predictive mixing rules for the YSIs of fuel surrogates based on their chemical compositions. 
5. To verify if the sooting behavior of a target fuel can be matched by a surrogate if the surrogate matches the fuel's carbon-type distribution.

\section{Experimental methods}

The experimental approach and devices used here have been discussed in detail previously [32] and are briefly reiterated here. Atmospheric pressure, axisymmetric, coflowing, nonpremixed, laminar methane/air flames were established on a Yale Coflow burner [39]. Sooting tendencies of pure compounds, diesel and jet fuels, and their surrogates (listed in Tables 1, 2, 3, and 4) were determined by doping them separately into the fuel of a flame and measuring two-dimensional soot volume fraction $\left(f_{v}\right)$ maps using color-ratio pyrometry. The fuel mixture - methane (mass fraction $Y_{\mathrm{CH}_{4}}=58.3 \%$ ), nitrogen $\left(Y_{\mathrm{N}_{2}}=41.2 \%\right)$, and a dopant $\left(Y_{\text {dopant }}=0.5 \%\right)$ - flows out of a $4 \mathrm{~mm}$ inner diameter tube and reacts with air that flows from the annular region between this tube and an $7.4 \mathrm{~cm}$ inner diameter concentric aluminum tube, which acts as a chimney. The nominal reactant flow rates were $282 \mathrm{~cm}^{3} / \mathrm{min}$ of $\mathrm{CH}_{4}, 112 \mathrm{~cm}^{3} / \mathrm{min}$ of $\mathrm{N}_{2}$, and $50,000 \mathrm{~cm}^{3} / \mathrm{min}$ of air. The dopants were added to the fuel on a constant mass-fraction basis in this work (instead of on a constant mole-fraction basis as in previous related works $[27,29,40]$ ) because, unlike the pure compounds studied earlier, the average molecular weights of the real fuels studied in this work were not known. All dopants were liquids at room temperature, with liquid-phase flowrates ranging from 96 to $146 \mu \mathrm{L}$ /hour depending on the liquid-phase mass density. Densities of all diesel and jet fuels and surrogates were measured as part of this work. The measured densities are consistent with values reported in the literature (where available).

Samples of diesel fuels and surrogates were provided by Chevron. Samples of jet fuels were obtained from Wright Patterson Air Force Base. All pure compounds were sourced from Sigma Aldrich. Fuel surrogates in Table 4 were prepared by blending their components volumetrically with Eppendorf Research Plus pipettes (accurate to $\pm 0.0008 \mathrm{~mL}$ ); component mass ratios were measured gravimetrically with a Mettler-Toledo xs105Du analytical balance (accurate to $\pm 0.02 \mathrm{mg}$ ). All dopants were dispensed into the gas-phase fuel mixture through a syringe pump (pump = Cole Parmer EW74900 , syringe $=$ Hamilton Gastight 1710). The needle of the syringe charged with the dopant was introduced into the fuel line through a septum in a stainless steel tee. The fuel line and fuel tube were heated to $145^{\circ} \mathrm{C}$ with temperature-controlled resistive tapes. At these thermal conditions, the vapor pressure [41] of $n$-hexadecane (1110 Pa), which was the least volatile of all dopants used, is approximately 25 times greater than its partial pressure in the fuel mixture ( $44 \mathrm{~Pa})$. Therefore, all liquid reactants vaporized upon injection and were swept as gases to the flame by other fuel components. Each dopant was allowed to flow for at least $30 \mathrm{~min}$ prior to data acquisition. Time-resolved flame luminosity measurements confirmed that all dopants achieved adsorption/desorption equilibrium with the walls of the fuel line and fuel tube within this 30 min interval.

Two-dimensional $f_{v}$ maps were measured using color-ratio pyrometry. This technique of measuring soot has been used in our previous work [32], and elsewhere in the literature [42-45]. Flames were 
Table 1: List of surrogate fuel components and their measured Yield Sooting Index in this study

\begin{tabular}{|c|c|c|c|c|}
\hline IUPAC (Common name) & Formula & CAS \# & $\mathrm{YSI}^{d}$ & Structure \\
\hline benzene $^{a}$ & $\mathrm{C}_{6} \mathrm{H}_{6}$ & $71-43-2$ & 100 & (0) \\
\hline$n$-hexane ${ }^{a}$ & $\mathrm{C}_{6} \mathrm{H}_{14}$ & $110-54-3$ & $\mathrm{O}$ & \\
\hline methylbenzene (toluene) & $\mathrm{C}_{7} \mathrm{H}_{8}$ & $108-88-3$ & 172.5 & \\
\hline methylcyclohexane & $\mathrm{C}_{7} \mathrm{H}_{14}$ & $108-87-2$ & 20.8 & \\
\hline 1,3-dimethylbenzene ( $m$-xylene) & $\mathrm{C}_{8} \mathrm{H}_{10}$ & $108-38-3$ & 193.1 & \\
\hline ethylbenzene & $\mathrm{C}_{8} \mathrm{H}_{10}$ & $100-41-4$ & 203.4 & \\
\hline 2,2,4-trimethylpentane (iso-octane) & $\mathrm{C}_{8} \mathrm{H}_{18}$ & $540-84-1$ & 23.8 & \\
\hline propylbenzene & $\mathrm{C}_{9} \mathrm{H}_{12}$ & $103-65-1$ & 181.0 & \\
\hline 1,2,4-trimethylbenzene ${ }^{b}$ & $\mathrm{C}_{9} \mathrm{H}_{12}$ & $95-63-6$ & 260.6 & \\
\hline 1,3,5-trimethylbenzene (mesitylene) & $\mathrm{C}_{9} \mathrm{H}_{12}$ & $108-67-8$ & $243 \cdot 3$ & \\
\hline 1,2-dihydronaphthalene (dialin) & $\mathrm{C}_{10} \mathrm{H}_{10}$ & $447-53-0$ & 352.1 & \\
\hline $1,2,3,4$-tetrahydronaphthalene ${ }^{b}$ (tetralin) & $\mathrm{C}_{10} \mathrm{H}_{12}$ & $119-64-2$ & 264.4 & \\
\hline decahydronaphthalene (decalin) & $\mathrm{C}_{10} \mathrm{H}_{18}$ & $91-17-8$ & 53.7 & \\
\hline$n$-butylcyclohexane ${ }^{b}$ & $\mathrm{C}_{10} \mathrm{H}_{2 \mathrm{O}}$ & $1678-93-9$ & 17.0 & \\
\hline$n$-decane & $\mathrm{C}_{10} \mathrm{H}_{22}$ & $124-18-5$ & $7 \cdot 4$ & \\
\hline 1-methylnaphthalene & $\mathrm{C}_{11} \mathrm{H}_{10}$ & $90-12-0$ & 471.2 & \\
\hline cyclohexylbenzene & $\mathrm{C}_{12} \mathrm{H}_{16}$ & $827-52-1$ & 224.4 & \\
\hline$n$-dodecane & $\mathrm{C}_{12} \mathrm{H}_{26}$ & $112-40-3$ & 9.8 & \\
\hline perhydrophenanthrene $^{c}$ & $\mathrm{C}_{14} \mathrm{H}_{24}$ & $5743-97-5$ & 76.4 & \\
\hline$n$-tetradecane & $\mathrm{C}_{14} \mathrm{H}_{30}$ & $629-59-4$ & 9.5 & \\
\hline 1,3,5-triisopropylbenzene ${ }^{c}$ & $\mathrm{C}_{15} \mathrm{H}_{24}$ & $717-74-8$ & 246.2 & \\
\hline 1,3,5-triisopropylcyclohexane ${ }^{c}$ & $\mathrm{C}_{15} \mathrm{H}_{30}$ & $34387-60-5$ & 46.0 & \\
\hline$n$-hexadecane & $\mathrm{C}_{16} \mathrm{H}_{34}$ & $544-76-3$ & 11.7 & \\
\hline $2,2,4,4,6,8,8$-heptamethylnonane ${ }^{b}$ (iso-cetane) & $\mathrm{C}_{16} \mathrm{H}_{34}$ & $4390-04-9$ & 31.0 & \\
\hline 2-methylheptadecane $e^{e}$ & $\mathrm{C}_{17} \mathrm{H}_{36}$ & $1560-89-0$ & 13.5 & \\
\hline$n$-octadecane $\mathrm{e}^{b}$ & $\mathrm{C}_{18} \mathrm{H}_{38}$ & $593-45-3$ & $15 \cdot 3$ & \\
\hline$n$-eicosane ${ }^{b}$ & $\mathrm{C}_{2 \mathrm{O}} \mathrm{H}_{42}$ & $112-95-8$ & 14.1 & \\
\hline
\end{tabular}

${ }^{a}$ YSIs of benzene and $n$-hexane are defined as 100 and o, respectively

${ }^{b}$ The YSIs of these compounds were measured in [37]

${ }^{c}$ The YSIs of these compounds were measured in [32]

${ }^{d}$ Experimental uncertainty \pm 5 YSI units or $\pm 5 \%$, whichever is greater

${ }^{e}$ Predicted using Eq 6 
Table 2: Measured YSI for some diesel and jet fuels

\begin{tabular}{llc}
\hline & Name & YSI \\
\hline \multirow{2}{*}{ Diesels [18] } & FD9A & 111.4 \\
& CFA & $\mathbf{1 2 2 . 2}$ \\
\hline & POSF 4658 & 75.5 \\
Jet fuels [34] & POSF 10264 & 49.6 \\
& POSF 10289 & 86.9 \\
& POSF 10325 & 70.3 \\
\hline
\end{tabular}

Table 3: CFA diesel surrogate-fuel compositions (mass fractions) from [19] and their measured YSI

\begin{tabular}{|c|c|c|c|}
\hline Name & Compound & $W_{i}$ & YSI \\
\hline \multirow{4}{*}{ VOA } & iso-cetane & 0.42 & \multirow{4}{*}{89.2} \\
\hline & $n$-hexadecane & 0.32 & \\
\hline & 1-methylnaphthalene & 0.15 & \\
\hline & decalin & 0.11 & \\
\hline \multirow{5}{*}{ VoB } & iso-cetane & 0.33 & \multirow{5}{*}{121.0} \\
\hline & $n$-octadecane & 0.32 & \\
\hline & tetralin & 0.15 & \\
\hline & 1-methylnaphthalene & 0.12 & \\
\hline & 1,2,4-trimethylbenzene & 0.08 & \\
\hline \multirow{8}{*}{ V1 } & iso-cetane & 0.35 & \multirow{8}{*}{102.8} \\
\hline & $n$-octadecane & 0.27 & \\
\hline & 1-methylnaphthalene & 0.11 & \\
\hline & tetralin & 0.11 & \\
\hline & \multirow{4}{*}{$\begin{array}{l}\text { 1,2,4-trimethylbenzene } \\
\text { decalin } \\
\text { butylcyclohexane } \\
n \text {-hexadecane }\end{array}$} & 0.05 & \\
\hline & & 0.04 & \\
\hline & & 0.04 & \\
\hline & & 0.03 & \\
\hline \multirow{9}{*}{$\mathrm{V} 2$} & 1,3,5-triisopropylbenzene & 0.17 & \multirow{9}{*}{137.1} \\
\hline & $n$-octadecane & 0.15 & \\
\hline & butylcyclohexane & 0.15 & \\
\hline & 1,3,5-triisopropylcyclohexane & 0.13 & \\
\hline & tetralin & 0.12 & \\
\hline & 1-methylnaphthalene & 0.11 & \\
\hline & 2-methylheptadecane & 0.10 & \\
\hline & perhydrophenanthrene & 0.06 & \\
\hline & n-eicosane & 0.01 & \\
\hline
\end{tabular}


Table 4: Jet fuel surrogate compositions and their measured YSI

\begin{tabular}{|c|c|c|c|}
\hline Reference & Compound & $W_{i}$ & YSI \\
\hline \multirow{2}{*}{ Bruno \& Smith [36] } & $n$-dodecane & 0.78 & \multirow{2}{*}{58.0} \\
\hline & 1,3,5-trimethylbenzene & 0.22 & \\
\hline \multirow{3}{*}{ Mensch et al. [23] } & iso-octane & 0.49 & \multirow{3}{*}{77.2} \\
\hline & 1,3,5-trimethylbenzene & 0.27 & \\
\hline & $n$-dodecane & 0.24 & \\
\hline \multirow{4}{*}{ Dooley et al. [24] } & $n$-dodecane & 0.50 & \multirow{4}{*}{57.3} \\
\hline & iso-octane & 0.24 & \\
\hline & propylbenzene & 0.20 & \\
\hline & 1,3,5-trimethylbenzene & 0.06 & \\
\hline \multirow{5}{*}{ Agosta et al. [35] } & iso-cetane & 0.35 & \multirow{5}{*}{128.1} \\
\hline & $n$-dodecane & 0.24 & \\
\hline & 1-methylnaphthalene & 0.22 & \\
\hline & methylcyclohexane & 0.13 & \\
\hline & decalin & 0.07 & \\
\hline \multirow{6}{*}{ Violi et al. $[20,38]$} & $n$-dodecane & 0.35 & \multirow{6}{*}{40.8} \\
\hline & tetradecane & 0.28 & \\
\hline & methylcyclohexane & 0.14 & \\
\hline & $m$-xylene & 0.11 & \\
\hline & iso-octane & 0.08 & \\
\hline & tetralin & 0.05 & \\
\hline
\end{tabular}


imaged at $f / 16$ through a Schott BG-7 filter with a $50 \mathrm{~mm}$ focal length lens by a Nikon D9o consumer camera. The D9o utilizes a CMOS sensor $(23.6 \mathrm{~mm} \times 15.8 \mathrm{~mm})$ with 12.2 million pixels $(4288 \times 2848)$ for an effective spatial resolution of $35 \mu \mathrm{m}$ per pixel in the plane of the flame. The spectral response of the CMOS sensor in this camera has been fully characterized by Long and coworkers [42]. All image enhancement options (sharpness, contrast, color, saturation, etc.) were set to either "normal" or "none", as applicable. The ISO was set to its lowest value, 200. The image files were saved in the camera's .NEF 12-bit lossless compressed raw format, and demosaiced using OMA [46]. Three-dimensional soot luminosity distributions were tomographically reconstructed from the raw flame images using the Gaussian basis-set expansion Abel transform method (BASEX) [47]. For each doped flame, 100 images were acquired over a $600 \mathrm{~s}$ interval following a 30 min equilibration period. The individual images were converted into $2 \mathrm{D} f_{v}$ distributions, which were averaged to improve signal/noise and ameliorate uncertainties associated with dopant flow rate fluctuations. The reconstruction procedure and all subsequent soot calculations were implemented using in-house Python code, which is available from the authors upon request.

To test our diagnostic procedure, we imaged a series of flames doped with 1-methylnaphthalene $(1 \mathrm{MN})$ at $Y_{\text {dopant }}$ ranging from $0.1 \%$ to $0.7 \%$. The data in Figure 1 show how the maximum radially integrated soot volume fraction $F_{v, \text { max }}$ (which is a measure of the total soot load in the flame and is defined in Eq 2 below) depends on $Y_{\text {dopant }}$. The data closely fit the straight line shown in the figure, indicating that the measured soot volume fractions in these flames depend linearly on $Y_{\text {dopant }}$ at these doping levels. Additionally, the linear response also indicates that the radiative soot emissions are not being optically trapped to a significant extent in the flames studied in this work (the sootiest flame studied in this work is the $Y_{1 \mathrm{MN}}=0.7 \%$ flame).

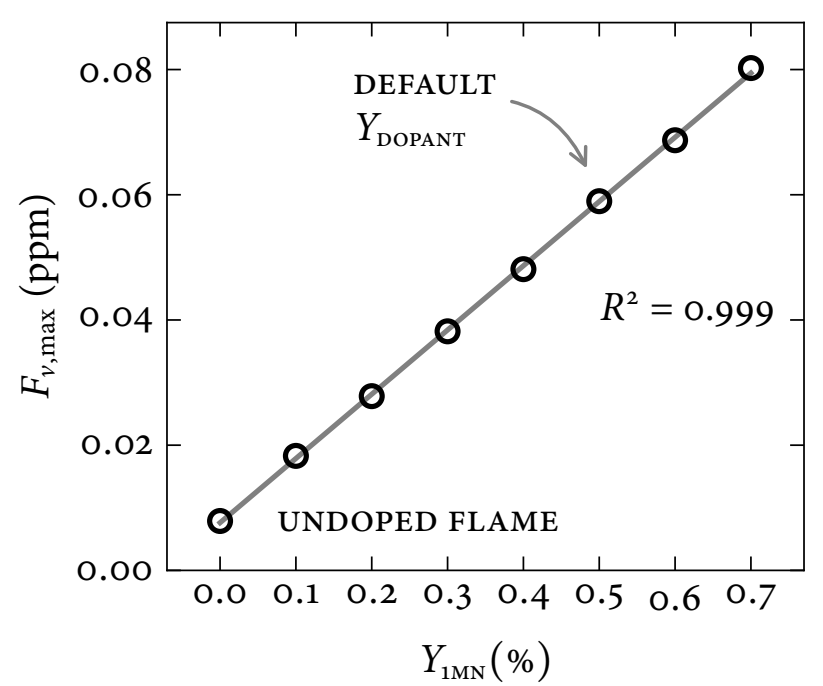

Figure 1: Maximum radially integrated $f_{v}$ (labeled $F_{v, \text { max }}$ ) for 1-methylnaphthalene doped flames at different doping levels. The grey line is a least-squares linear fit. 


\section{Results and Discussion}

\subsection{Soot volume fractions}

In this study, we measured 2D soot volume fraction $\left(f_{v}\right)$ maps for methane flames doped with 27 pure compounds, 6 diesel and jet fuels, and 9 fuel surrogates. Figure 2 shows some representative results. Hexane and benzene are hydrocarbons used to define the YSI scale (see Eq 1 above), while POSF 4658 and CFA are reference Jet-A and \#2 ultra-low sulfur diesel certification fuels, respectively. The fuel tube ranges from $-2 \leq r \leq 2 \mathrm{~mm}$ in each of the panels in Figure 2, with the coflowing air around it. The $f_{v}$ maps were cropped such that height above burner, $z=0 \mathrm{~mm}$ corresponds to the top edge of the fuel tube. Because the color ratio pyrometry diagnostic is based on radiative emissions from flame-heated soot particles, $f_{v}$ measurements are only available at flame locations with detectable soot luminosity. Similar $f_{v}$ maps were obtained for all compounds, fuels, and surrogates listed in Tables 1 4 and are available upon request from the authors. All flames were non-smoking, with $f_{v}$ peaking at the centerline, and measurable $f_{v}$ occurring at $z \geq 20 \mathrm{~mm}$. The doped flames were qualitatively similar to the undoped flame; however, increased $f_{v}$ was detected at all locations in all doped flames compared to the undoped case.
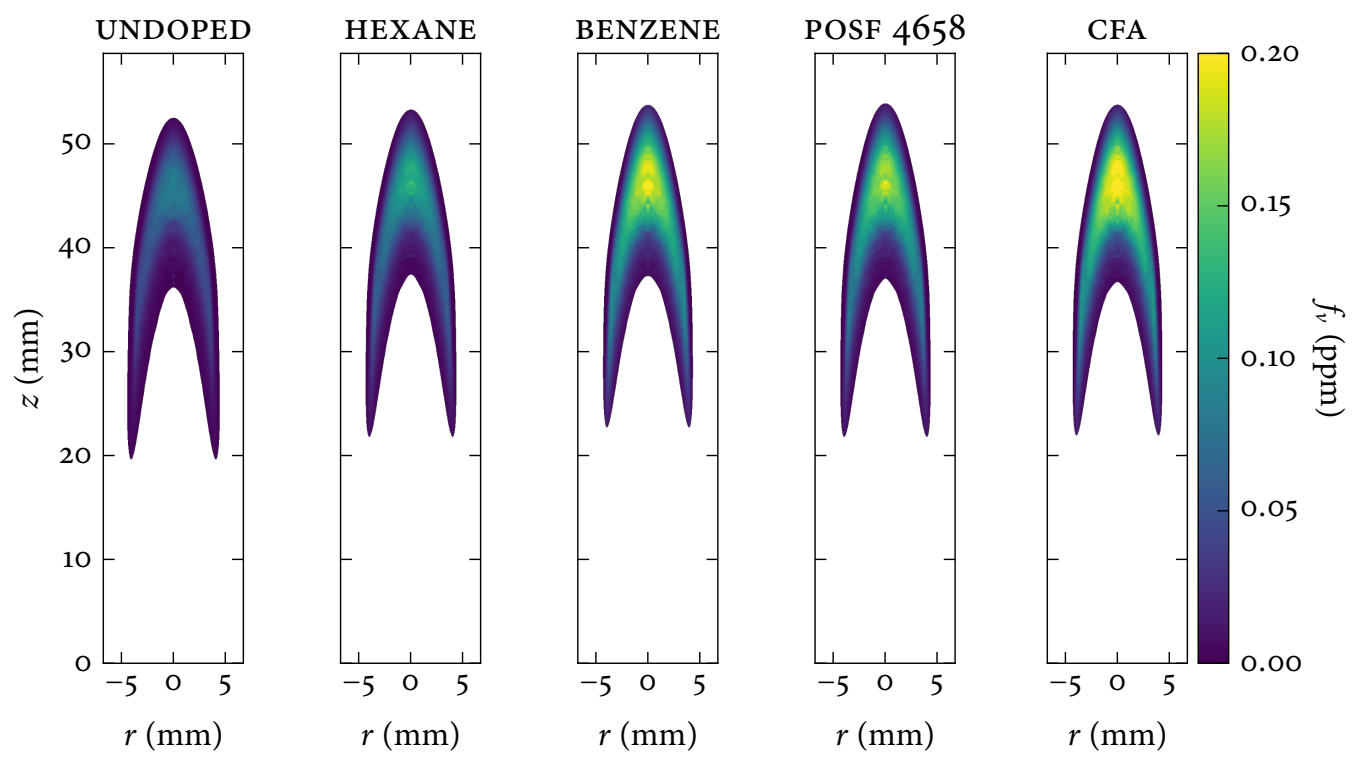

Figure 2: Two-dimensional maps of soot volume fraction in an undoped methane flame (left) and methane flames doped with various test compounds and fuels in Tables 1 and $2 . Y_{\text {dopant }}=0.5 \%$ in all doped flames. 
3.2. Yield Sooting Index

Radially integrated soot volume fractions $F_{v}(z)$ can be calculated from the full 2D soot maps in Figure 2.

$$
F_{v}(z)=\frac{1}{\pi R^{2}} \int_{0}^{R} 2 \pi r f_{v}(r, z) d r
$$

where $R=6 \mathrm{~mm}$ is the outer edge of the flame image. $F_{v}(z)$ is an evaluation of the actual soot load at a given height in the flame [30]. Figure 3 shows $F_{v}(z)$ for the flames in Figure 2. Using the maximum value of $F_{v}(z)$, we can define the dopant's Yield Sooting Index (YSI) using Eq 1 with the apparatus-specific parameters $A$ and $B$ chosen such that YSI (hexane) $\equiv 0$ and YSI (benzene) $\equiv 100$. Using the 2D $f_{v}$ measurements and Eqns 1 and 2, we calculated the YSIs of all compounds, fuels, and surrogates. YSI measurements for all dopants were repeated at least thrice, with average repeatability of $\pm 4 \%$. The average of the repeated YSI measurements for the dopants are listed in Tables $1-4$.

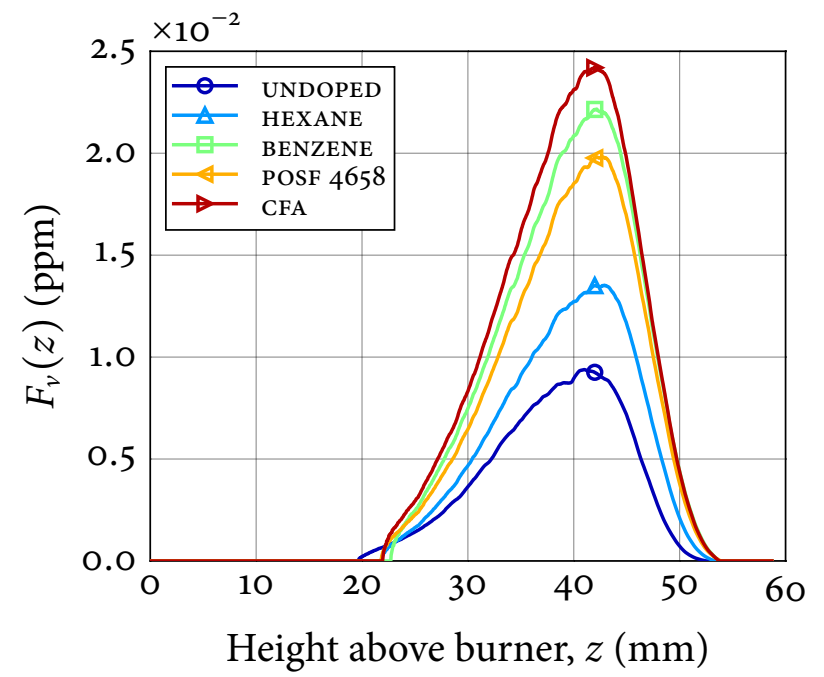

Figure 3: Radially integrated soot volume fractions $F_{v}(z)$ for the flames in Figure 2.

3.3. Literature sooting tendency comparisons

\subsubsection{Threshold Sooting Index}

Calcote and Manos [48] defined a hydrocarbon's Threshold Sooting Index (TSI) as

$$
\mathrm{TSI}=a(M W / S P)+b
$$

based on the compound's molecular weight $(M W)$ and smoke point $(S P)$. The parameters $a$ and $b$ were used to establish a uniform scale for the TSI and account for smoke point apparatus differences, analogous to the process used to determine octane and cetane ratings for fuels used in internal combustion engines. The TSI is significant for being the first numerical scale for sooting tendencies 


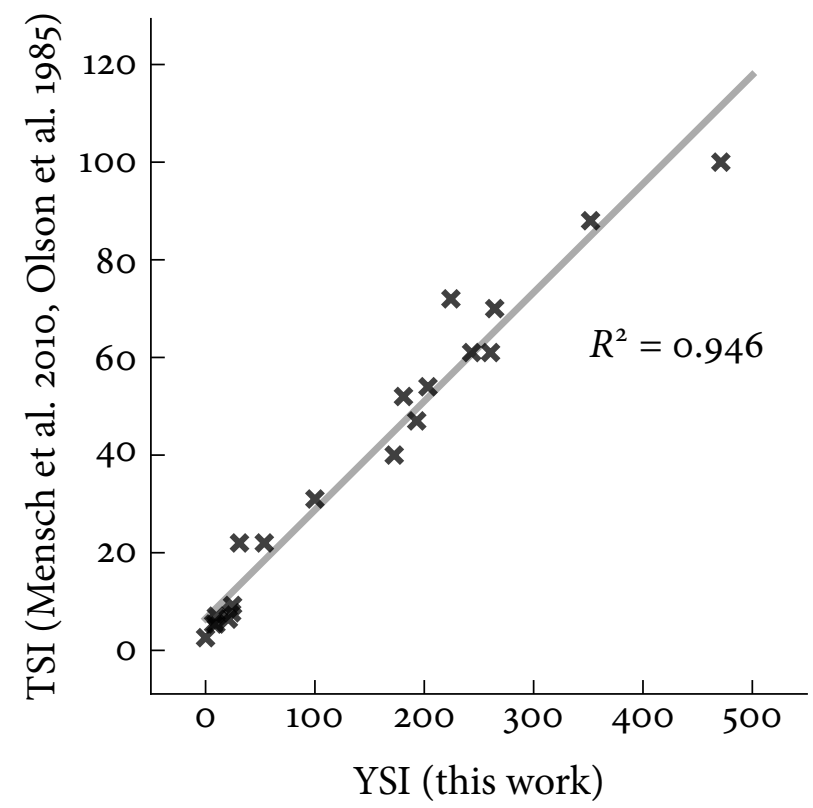

Figure 4: Threshold sooting indices (TSIs) vs Yield sooting indices (YSIs) for the pure compounds studied in this work, whose TSI values were available from Mensch et al. [23] and Olson et al. [49]. The grey line is a least-squares linear fit.

of pure hydrocarbons which was device independent and inherently determined by a compound's molecular structure. Olson et al. [49] applied this TSI model to smoke point results obtained on the ASTM standard smoke point lamp [26]. They incorporated information from their measurements and from the literature and provided a list of "suggested values" for the TSI of a large range of hydrocarbons. Later, in 2010, Mensch et al. [23] reviewed and collated various literature sooting tendency data sets to assemble a consistent set of TSI values for many potential components of jet fuel surrogates.

Figure 4 shows a plot of the YSIs of the compounds listed in Table 1 vs their TSIs from Olson et al. [49] and Mensch et al. [23] (for compounds listed in both Ref [49] and [23], the value given in the latter is chosen). It can be seen that the YSIs of the compounds measured in this work correlate well with their TSIs reported in $[23,49]$ over a large sooting range, covering $n-$, iso-, and cycloalkanes, and single-, and multi-ring aromatics. This agreement between the YSI and TSI allows us to draw two conclusions: (1) Quantifying sooting tendencies based on maximum soot yield in a doped methane/air coflow flame (YSI) is consistent with sooting tendency measurements made with each compound at its own smoke point (TSI). (2) Because the TSI values of these compounds (derived from smoke point measurements in flames fueled by pure compounds) agree with their YSI values (derived from soot yield measurements in methane flames doped with these compounds), the choice of methane as the base fuel, and its associated chemical implications (such as a preponderance of methyl radicals in the flame), does not confound the sooting tendency measurement. 


\subsubsection{Constant mole fraction YSI}

McEnally and Pfefferle reported the sooting tendencies of some of the aromatic hydrocarbons in Table 1 in an earlier work [27] in which they introduced the maximum soot yield based YSI approach to measuring sooting tendency. Figure 5 plots the YSIs of the compounds in Table 1 measured in the current work vs their YSIs from [27]. This comparison between the previous measurements, where the compounds were doped into the flame on a constant mole fraction basis, and the current measurements, where the compounds are doped into the flame on a constant mass fraction basis, was done as a sanity check. In general, sooting tendency measurements for aromatics in this work are qualitatively consistent with previous YSI measurements. The actual YSI values from this work and from [27] are expected to disagree for two reasons: (1) The YSI values in [27] were scaled such that benzene $\equiv 30$ and 1,2,-dihydronaphthalene $\equiv 100$, whereas in this work, they are scaled to hexane $\equiv \mathrm{o}$ and benzene $\equiv 100$. This explains the difference in the relative scale of YSI values between the horizontal and vertical axes in Figure 5. (2) The compounds in [27] were doped into the methane/air flame at a constant mole fraction of $400 \mathrm{ppm}$. In this work, the same compounds were doped at a constant mass fraction of $0.5 \%$ by weight. Differences in molecular weights and densities between the compounds leads to differences ${ }^{1}$ in the actual doping levels of these compounds between this work and [27]. This accounts for deviations from perfect linear agreement (relative spread around the linear trendline) seen in Figure 5.

\footnotetext{
${ }^{1}$ For example, 1,3-dimethylbenzene (13DMB) and 1,3,5-trimethylbenzene (135тмB) are two compounds whose YSI were measured in this work and [27]. 13 Dмв and 135тмв have very similar densities ( $0.868 \mathrm{~g} / \mathrm{ml} \mathrm{and} \mathrm{o.864} \mathrm{g/ml} \mathrm{respectively);}$ therefore, in this work, they were doped into the flame with similar liquid flow rates. However they have different molecular weights (106.2 $\mathrm{g} / \mathrm{mol}$ and $120.2 \mathrm{~g} / \mathrm{mol}$ respectively), and consequently, in [27] the liquid flow rate of $135 \mathrm{TMB}$ was approximately $13 \%$ greater than 13Dмв. These relative differences in doping levels manifest as differences in measured soot yields between this work and [27].
} 


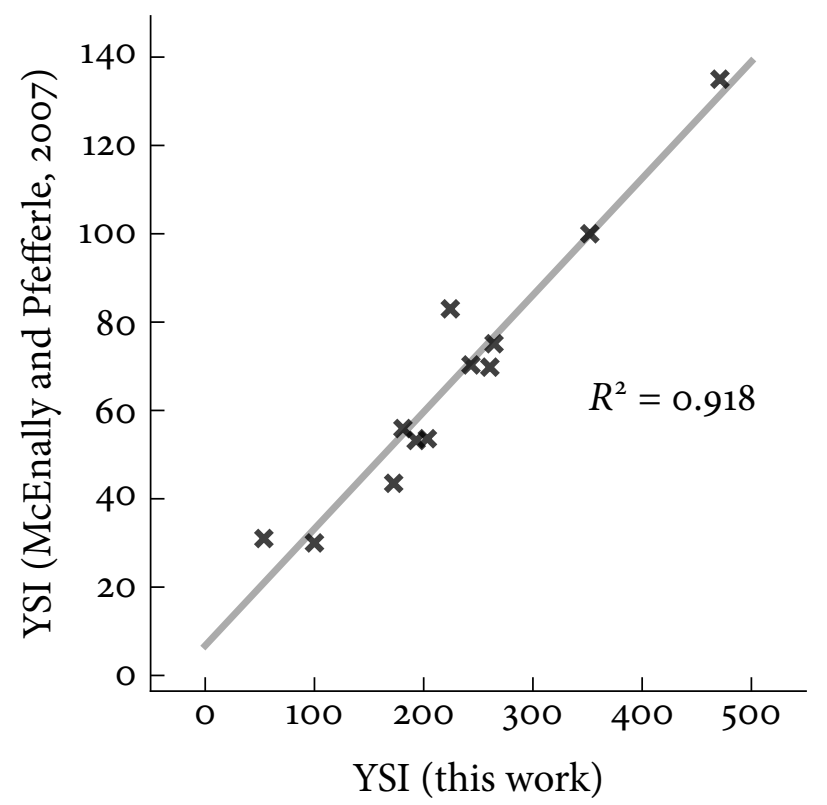

Figure 5: Comparison of yield sooting indices (YSIs) for aromatics doped at constant mole fractions (from McEnally and Pfefferle, 2007 [27]) versus aromatics doped at constant mass fractions (in this work, see Table 1). The grey line is a least-squares linear fit.

3.4. Structural predictions

3.4.1. Hydrogen content

The hydrogen content of a hydrocarbon (either as $\mathrm{H} / \mathrm{C}$ ratio or $\mathrm{H} \%$ by weight) is one of the oldest parameters used to predict its sooting tendency [50]. Typically, higher hydrogen content correlates with a greater degree of saturation and a lower tendency to form soot. However, limited predictive capability $[48,51]$ has been attributed to this parameter, for two major reasons: (1) the tendency to form more soot with decreasing H/C is a weak trend, and (2) a compound's hydrogen content is coupled with its adiabatic flame temperature and therefore the relationship between hydrogen content and sooting tendency could be a manifestation of thermal rather than chemical effects.

Figure 6 shows the relationship between the sooting tendency of a hydrocarbon (quantified by its YSI) and its hydrogen content (H\% by mass). The line is drawn as a visual aid. The overall trend suggests sooting tendency increases with decreasing hydrogen content in a hydrocarbon. This is consistent with the observed sooting tendencies of alkanes $<$ cycloalkanes $<$ aromatics in flames and engine studies [52]. However, the single-ring aromatics ( $\nabla$ in Figure 6 ) in our dataset do not follow this trend. These aromatics include benzene, and alkyl-substituted benzenes, starting with a methyl group (toluene) and ending with tri-isopropylbenzene (тіPв). These alkyl substitutions increase the compound's YSI, while also increasing its overall hydrogen mass fraction. Contrary to what would be expected from the increase in hydrogen content, the presence of these non-aromatic substitutions on 
benzene ring do not have a dilutive effect on its sooting tendency. Instead, these alkyl substitutions enhance soot formation because they can provide access to additional pathways for aromatic ring growth [27], which has been shown to be the rate determining step in soot formation in nonpremixed flames [53].

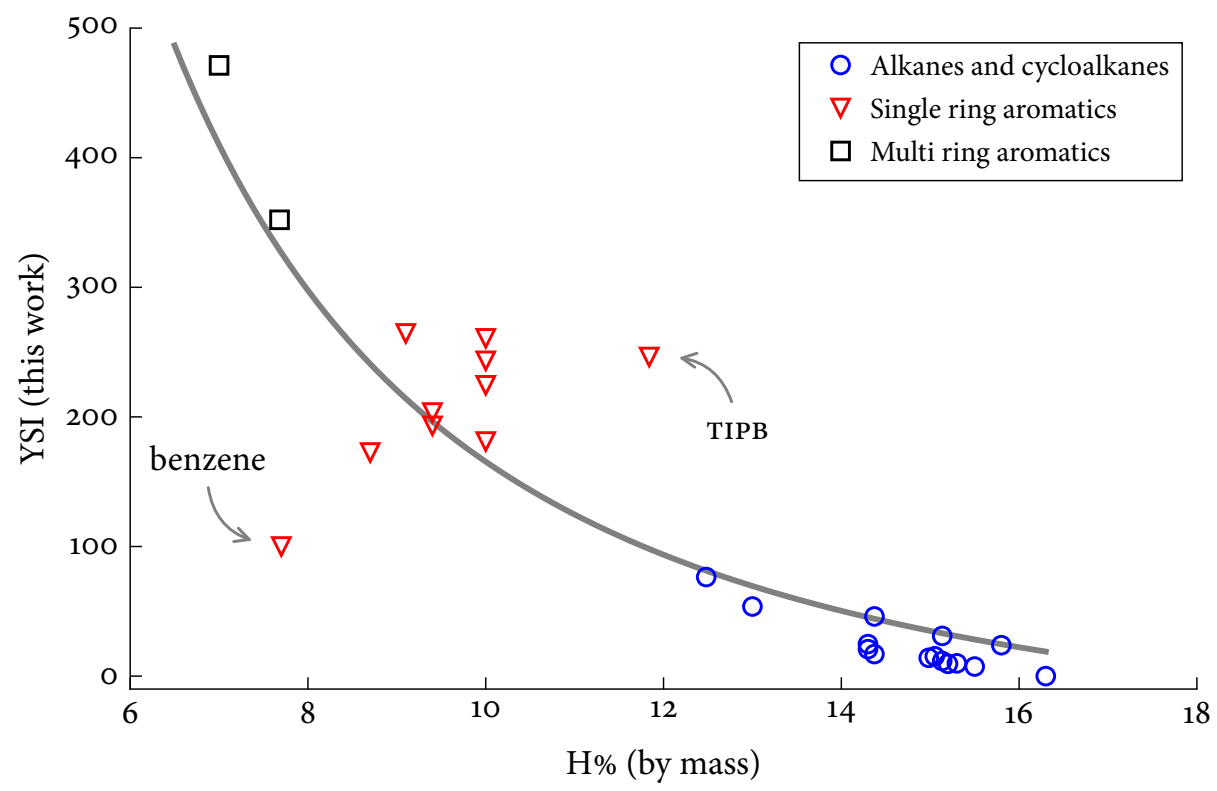

Figure 6: Comparison of hydrogen content (H\% by mass) vs sooting tendency (YSI) for 27 hydrocarbons listed in Table 1.

3.4.2. Double Bond Equivalent

The double-bond equivalent (DBE) of a hydrocarbon $\mathrm{C}_{n} \mathrm{H}_{m}$ is defined as

$$
\mathrm{DBE}=1+n-m / 2
$$

It accounts for the level of unsaturation and presence of cyclic ring structures in a hydrocarbon. The DBE of fuels has been used to represent the effects of fuel molecular structure on their sooting behavior in the literature. Hanson and Rouvray [54] used the DBE (which they referred to as the hydrogen deficiency index, HD) in their model to correlate the TSI of hydrocarbon fuels with topological indices. Aikawa et al. [55] used the DBE in the definition of their empirical particulate matter index (PMI) as a way to incorporate fuel molecular structure effects on PM emissions from engines.

Figure 7 shows the relationship between the DBE and sooting tendency (YSI) of compounds listed in Table 1. The line, a quadratic fit to the data, is drawn as a visual aid. The overall trend indicates that sooting tendencies increase with increasing DBE. However, the large range of YSI values for any given DBE in Figure 7, especially for DBE $=0$ and 4 , highlights some of the shortcomings of 
using the DBE as a predictive sooting tendency parameter. DBE does not distinguish between any alkanes (which all have a DBE of o, regardless of size or degree of branching). For instance, hexane and 2,2,4,4,6,8,8-heptamethylnonane (HMN) both have a DBE of o, but YSI of o and 31.o, respectively. Similarly, DBE does not distinguish between any aromatic compound and any of its alkyl-substituted counterparts. Benzene and 1,3,5-triisopropylbenzene (TIPB) both have a DBE of 4 (the alkyl side-chains in тIPв do not contribute to the DBE), but their YSIs are 100 and 246.2, respectively. These issues rise primarily from DBE's limited numerical "resolution". DBE can only be integers for pure compounds, which effectively compresses the fuel structure-specific sooting information into coarse bins.

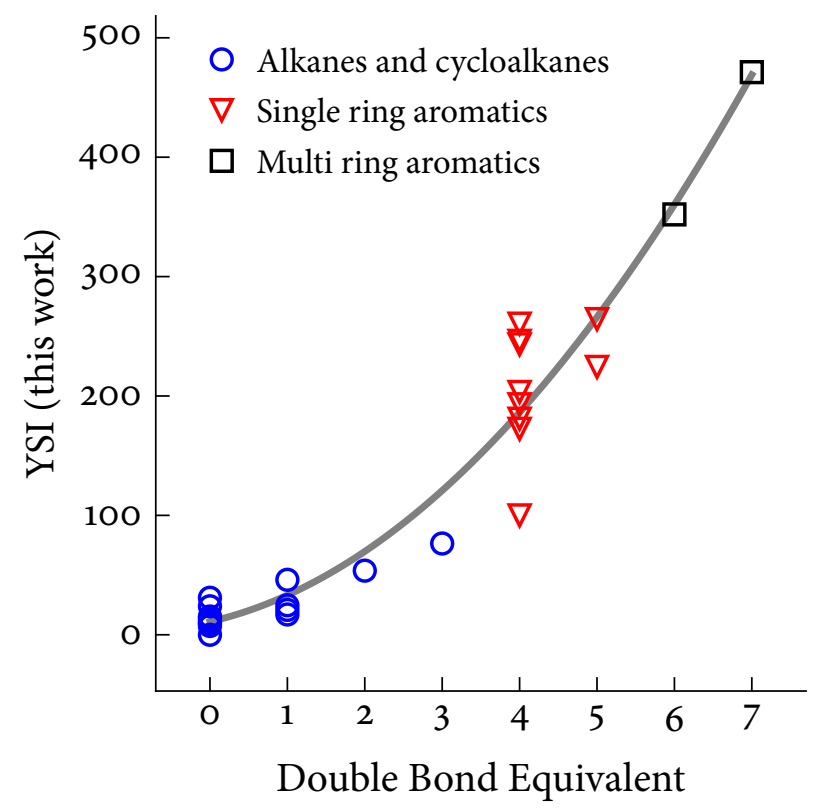

Figure 7: Comparison of Double Bond Equivalent vs sooting tendency (YSI) for 27 hydrocarbons listed in Table 1.

\subsubsection{NMR Carbon-type decomposition}

${ }^{13} \mathrm{C}$ (carbon) and ${ }^{1} \mathrm{H}$ (proton) nuclear magnetic resonance (NMR) spectroscopy based techniques have proven useful in quantifying the compositional characteristics of fuels in the literature $[18,56-60]$. These NMR techniques yield fuel composition on a per-carbon-atom basis, and can provide better structure-specific sooting information than "lumped parameters" [61] such as hydrogen content or DBE, owing to the greater resolution ${ }^{2}$ of the carbon bond types within each molecule. Mueller et al. [18] used these carbon and proton NMR techniques to quantify the presence of 11 different carbon types (CT, see Table 5) in two reference diesels and their surrogates.

\footnotetext{
${ }^{2}$ For example, $n$-decylbenzene would be characterized as "aromatic" in an analysis based on hydrocarbon-molecule class, but an NMR analysis, as employed by Mueller et al. [18], would show that only $37.5 \mathrm{~mol} \%$ of the $n$-decylbenzene carbon is
} 
We have developed Multiple Linear Regression (MLR) models to represent the effects of these CTs on the sooting behavior of the compounds listed in Table 1 and in the literature [27, 40]. Similar NMR-based carbon-type MLR models have been developed in the literature to regress various physical (density, viscosity, final boiling point) [6o] and chemical (smoke point, aromatics content, heat of combustion, cetane index, octane number) $[56,58,59,62]$ properties of diesels and jet fuels. In the MLR models in this work, the scalar dependent variable is the YSI of the compound, and the explanatory (independent) variables are the number of carbon atoms of each CT in a molecule of the compound.

$$
\begin{aligned}
\text { YSI }(\text { predicted }) & =\sum_{j} N_{i j} C_{j} \\
\min \chi^{2} & \left.\left.=\sum_{i=1}^{n}[\text { YSI (expt. })-\text { YSI (pred. }\right)\right]^{2}
\end{aligned}
$$

$N_{i j}$ is the number of carbon atoms of type $j$ in compound $i$, and $C_{j}$ is the specific contribution of $\mathrm{CT} j$. The various $C_{j}$ are determined by least-squares fitting of Eq 5 to the experimental YSI, which is cast as an optimization problem (Eq 6). This analysis is analogous to the Benson group additivity approach [63] used to estimate the sooting tendency of hydrocarbons [29, 64, 65], with the important distinction being that the "groups" considered here are the aforementioned CTs, whose abundance in real fuels can be quantified experimentally with NMR spectroscopy. Table 5 lists the optimized contributions of each carbon type based on the YSI values of compounds in Table 1.

Figure 8 shows the correlation between YSI (predicted) and YSI (experimental) using the optimized values of $C_{j}$ for three different YSI databases. Figure 8(a) shows the correlation for 26 compounds ${ }^{3}$ whose YSIs were measured in this work and are listed in Table 1; all 11 CTs were represented, with $R^{2}=0.975$. Figure $8(\mathrm{~b})$ shows the correlation $\left(R^{2}=0.955\right)$ for 52 aromatic hydrocarbons, whose YSIs were measured in [27]. Figure $8(\mathrm{c})$ shows the correlation $\left(R^{2}=0.992\right)$ for 45 aliphatic hydrocarbons, whose YSIs were measured in [40]. Because this last database did not feature any aromatic or multicyclic compounds, only 6 CTs $(\mathrm{CT} 1-5,11)$ were used in the MLR model.

All three datasets satisfied several empirically established criteria regarding size of data set, range of property values, and maximum permissible experimental error [66]. To verify that the goodness of fit observed for these regressions was not due to the presence of too many free parameters (11 CTs), we reduced the number of distinct carbon types and developed a "simplified" MLR model for the 45 aliphatic hydrocarbons in the YSI database in [40]. We achieved this reduction by treating secondary (and tertiary) carbon atoms in a linear chain and a ring as the same, i.e., by lumping CT2 + СT4 and СT3 + СT5. Figure 8(d) shows the correlation between experimental and predicted YSIs for this simplified model. We see that by ignoring the difference between a carbon atom in a linear chain versus a cyclic ring, the predictive power of the MLR worsens significantly, with the alkanes and

aromatic in character, with the balance having characteristics more representative of alkanes.

${ }^{3}$ The YSI of 2-methylheptadecane was not measured experimentally and did not feature in the regression. 
348 hydrocarbons of relevance to diesel and jet fuel surrogate formulation.

Table 5: Carbon atom types distinguished by ${ }^{13} \mathrm{C}$ and ${ }^{1} \mathrm{H}$ NMR-spectroscopy classification technique. Occurrences and $C_{j}$ are based on the YSIs of compounds in Table 1.

\begin{tabular}{|c|c|c|c|c|}
\hline Name & Label & Example & Occurrences & $C_{j}$ \\
\hline $\mathrm{CH}_{3}$ & CT1 & & 57 & -4.49 \\
\hline$n$-alkane $\mathrm{CH}_{2}$ & СT2 & & 106 & 1.52 \\
\hline iso-alkane $\mathrm{CH}$ & СТ3 & & 9 & 2.11 \\
\hline cyclo-alkane $\mathrm{CH}_{2}$ & CT4 & & 40 & 2.71 \\
\hline cyclo-alkane to alkyl-chain $\mathrm{CH}$ & CT5 & & 6 & 19.02 \\
\hline cyclo-alkane to cyclo-alkane $\mathrm{CH}$ & ст6 & & 6 & 13.07 \\
\hline aromatic $\mathrm{CH}$ & CT7 & & 58 & 20.61 \\
\hline aromatic to alkyl-chain $\mathrm{C}$ & Ст8 & & 16 & 70.23 \\
\hline aromatic to cyclo-alkane $\mathrm{C}$ & СТ9 & & 2 & 85.55 \\
\hline aromatic to aromatic $\mathrm{C}$ & CT10 & & 4 & 112.09 \\
\hline aliphatic C & CT11 & & 4 & 23.70 \\
\hline
\end{tabular}

cycloalkanes clustering into two different groups. This worsening of the fit suggests that the different CTs in Table 5 are necessary to fully describe the compounds' sooting behavior, and the goodness of fit demonstrated in Fig 8 (a), (b), and (c) is likely not due to overfitting of the data.

Other MLR models developed to predict sooting tendencies in the literature have incorporated topological indices [66], such as the Balaban index [54], the Wiener index [64], the branching index [62], etc. in their regression models. These topological parameters, which quantify the "compactness" of a compound, can provide means to encode the difference between isomers of a compound which differ from each other based on the location of a side chain on the carbon backbone (e.g., 2-methylheptane/3methylheptane, or $o-/ m-/ p$-xylene). We have not observed a significant variation in the sooting tendency between such structural isomers (based on an examination of YSI values of such isomeric cohorts from $[27,40])$, and thus have not included such topological indices in the above regression in the interest of model simplicity and ease of use.

The good agreement between the measured and predicted YSIs for all three datasets indicates that the NMR-based CT characterization can capture essential structure-specific sooting information for

\subsection{Sooting tendencies of real fuels and surrogates}

3.5.1. Smoke points

The smoke point of a fuel is defined in ASTM D1322 [26] as the maximum height of a smokeless laminar diffusion flame of the fuel burned in a wick-fed lamp of specified design. Any increase in fuel flowrate, and consequently the flame height, results in soot escaping from the tip of the flame. 
Table 6: Prevalence of carbon atom types in hydrocarbons in three YSI databases. For example, there were 12, 67, and o compounds with the CT7 carbon type in this work, M\&P 2007 [27], and M\&P 2011 [40], respectively.

\begin{tabular}{lccccccccccc}
\hline Carbon type & CT1 & CT2 & CT3 & CT4 & CT5 & CT6 & CT7 & CT8 & CT9 & CT10 & CT11 \\
\hline This work & 21 & 13 & 5 & 7 & 4 & 2 & 12 & 9 & 1 & 2 & 2 \\
M\&P 2007 & 55 & 30 & 8 & 7 & 2 & 1 & 67 & 60 & 5 & 14 & 4 \\
M\&P 2011 & 41 & 31 & 19 & 15 & 11 & 0 & 0 & 0 & 0 & 0 & 7 \\
\hline
\end{tabular}
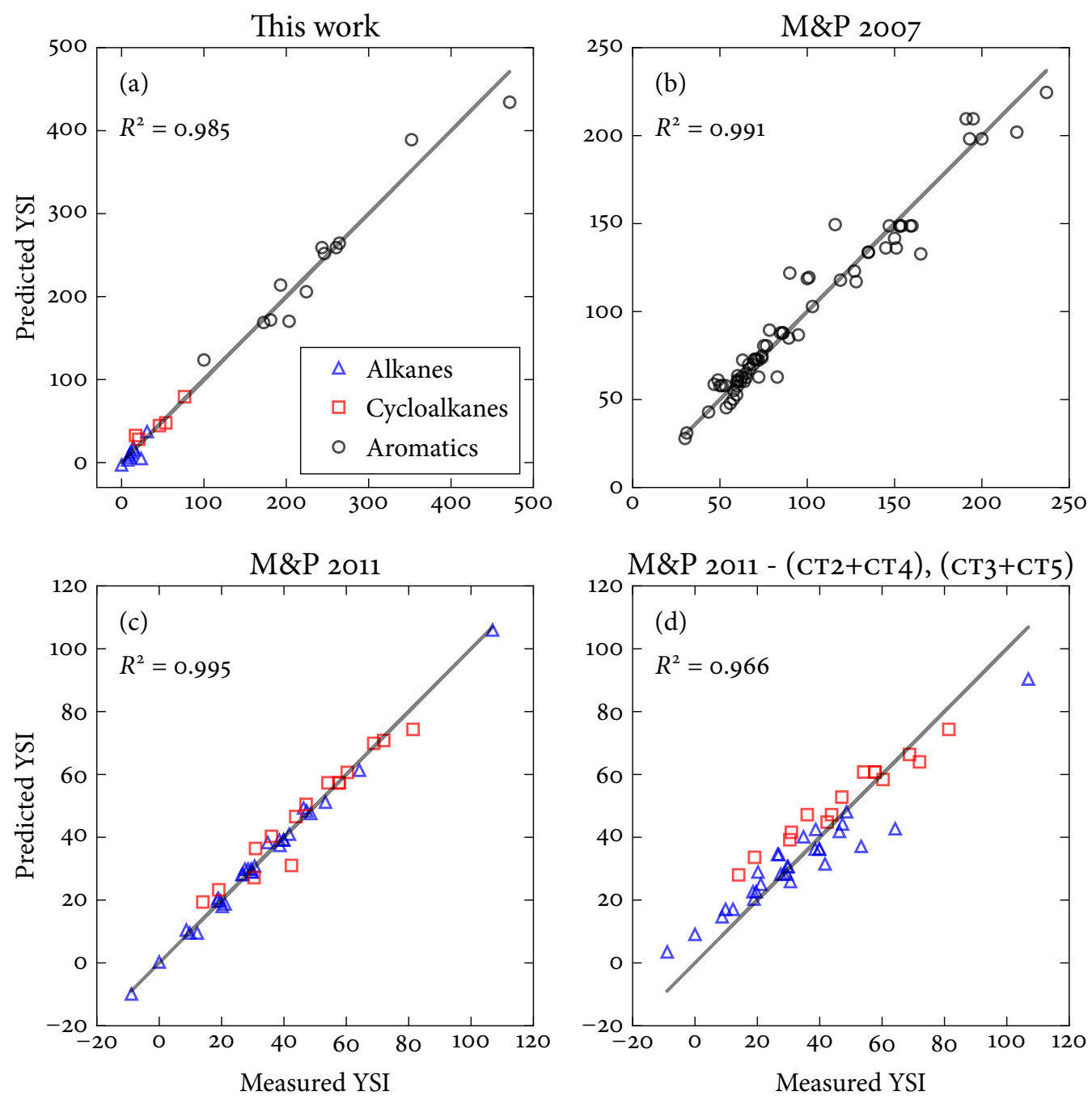

Figure 8: Correlation between YSIs of hydrocarbons predicted with Eq 5 using optimized carbon-type contribution values, and measured experimentally (from three different YSI databases). The grey lines in (a), (b), (c), and (d) are the $x=y$ lines, indicating perfect agreement. 
Because this onset of soot breakthrough occurs at different flame heights for different fuels, the smoke point has traditionally been considered an important practical predictor of sooting tendency [23]. For instance, the smoke point and parameters based on the smoke point are used to estimate the sooting propensities of jet fuels, with a lower smoke point indicating a greater propensity to form soot.

Figure 9 compares the smoke points of some fuels and surrogates measured in the literature and their YSIs (Tables 2 - 4) measured in this work. Black circles (O) indicate a reference diesel (CFA) and its surrogates, whose smoke point measurements were reported in [8]. Red triangles $(\nabla)$ indicate a reference jet fuel (POSF 4658) and its surrogate, whose smoke point measurements were reported in [67]. Blue squares $(\square)$ indicate three reference jet fuels, samples and smoke point measurements of which were obtained from Wright Patterson Air Force Base, $\mathrm{OH}[34,68]$. The dashed lines are drawn as a visual aid. For all three smoke point datasets, decreasing smoke points correlate very well with increasing YSIs. These results, along with the results discussed in \$3.3.1, lend credence to the assertion that the doped methane flame strategy of measuring sooting tendency is consistent with pure fuel based flame studies of sooting tendency. There is no evidence that the presence of methane as the base fuel in the flames studied in this work confounds the reported sooting tendency measurements.

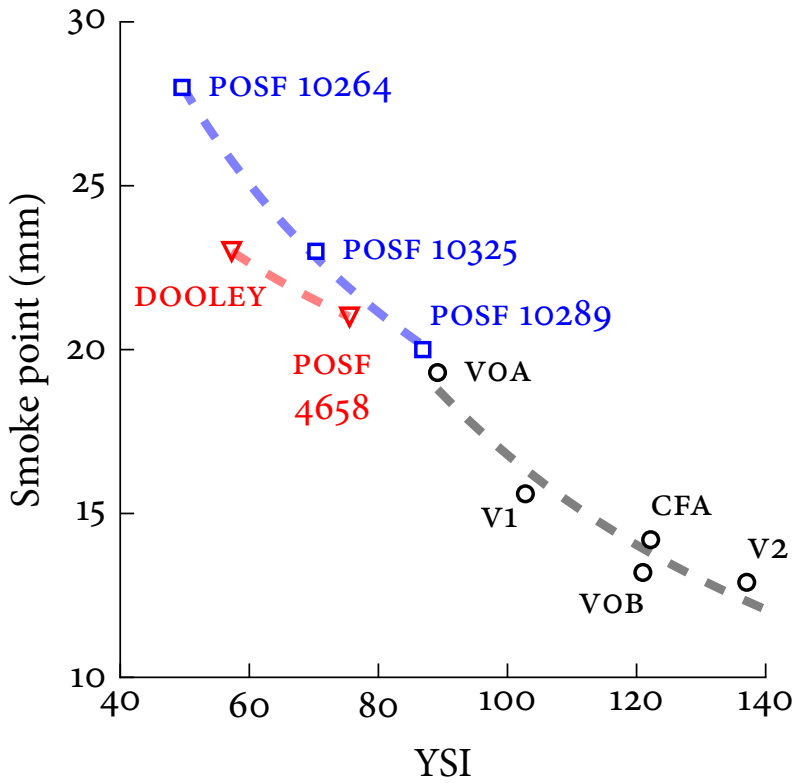

Figure 9: Comparison of smoke points vs sooting tendencies (YSI) for diesel, jet fuels, and their surrogates.

\section{3.5.2. Aromatic content}

The aromatic content of a fuel is another important practical indicator of its sooting tendency [61]. It is commonly reported as a volume percent as determined by either a fluorescent indicator adsorption test (ASTM D1319 [69]) or a newer supercritical fluid chromatography method (ASTM 
D5186 [70]). The maximum aromatic content is regulated in many diesels [71] and jet fuels [26]. This has motivated attempts to match the proportion and distribution of aromatics between fuels and their surrogates as a way to ensure fuel surrogates match the sooting behavior of their target fuels.

To understand the relationship between fuel aromatic content and sooting tendency, in Figure 10 we plot the reported aromatics vol\% (via ASTM D1319) for some diesel and jet fuels in the literature $[18,34]$ vs their YSIs measured in this work (Table 2). The line is a linear best fit line to all data points except the one outlier labeled FD9A.

In general, the sooting tendency of all fuels correlates well with their aromatic content as long as their ratio of polyaromatics/monoaromatics is similar. The anomalous behavior of FD9A can be explained by comparing the reported hydrocarbon distributions of the fuels studied here. FD9A (FACE Diesel \#9 Batch A) is one of nine Fuels for Advanced Combustion Engines (FACE) reference diesel fuels developed to study the effects of fuel-property variations on diesel combustion in engines [33, 72]. Though this fuel was selected for its moderate total aromatics content (one of the three fuel-properties which varied amongst fuels in the FACE project), Mueller et al. [18] noted that the fuel exhibited anomalously high levels of $\mathrm{C}_{8}$ and $\mathrm{C}_{9}$ monoaromatics. The other diesel and jet fuels studied in this work showed $[18,34]$ a more-typical distribution of hydrocarbon class as a function of carbon number. The preponderance of monoaromatics in FD9A would contribute significantly towards the net aromatic fraction of the fuel while contributing incommensurately to its YSI (cf. the difference between the YSI of toluene (monoaromatic, YSI $=172.5)$ and 1-methylnaphthalene (diaromatic, YSI $=471.2)$ in Table 1).

These findings suggest that while the sooting behavior of a fuel is largely dependent on the aromatics present in the fuel, a lumped parameter such as aromatics volume percent can be inadequate for predicting its sooting tendency. To develop surrogates with fidelity to the sooting behavior of these fuels, it is important to characterize the nature of their aromatic content.

\subsubsection{Sooting tendency of real fuel surrogates}

In addition to the 27 pure compounds and 6 real fuels listed in Tables 1 and 2, we measured the sooting tendencies of 4 diesel and 5 jet fuel surrogates (see Tables 3 and 4 ). The measured YSIs of these surrogates agree with established literature sooting tendency information, where available.

Mueller et al. [19] reported the smoke points for the CFA diesel and its four surrogates. The YSIs of the fuel and surrogates are consistent with these smoke points (cf. Fig 9); the voA surrogate has the highest smoke point and lowest YSI (and vice versa for v2). Similarly, Dooley et al. [24] reported in a separate work [73] that their surrogate $(\mathrm{TSI}=20.4)$ had a lower sooting tendency than its target jet fuel, POSF 4658 (TSI = 24.2), which is consistent with the measured YSI values in this work. Finally, Mensch et al. [23] reported that their surrogate matched the TSI of its target JP-8 fuel (TSI $=22$ ) to within experimental uncertainty. Because there is significant variability in the composition of the JP-8 fuel (unlike a reference blend such as POSF 4658), it is difficult to directly compare the YSI of the Mensch surrogate to the jet fuels in this work. However, if we average the YSI of the two JP-8/Jet-A fuels with "normal" properties in Table 2 (POSF 4658 and POSF 10325), we see that the averaged YSI (72.9) agrees with the YSI of the Mensch surrogate (77.2) to within the experimental uncertainty of \pm 5 YSI units. 


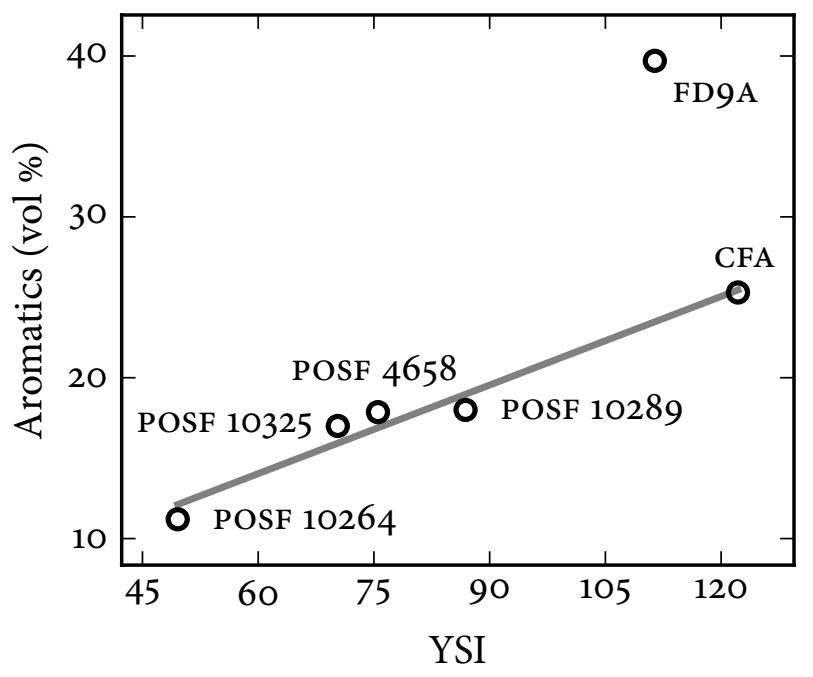

Figure 10: Comparison of aromatic content (in vol\%) vs sooting tendencies (YSI) for some diesel and jet fuels. $R^{2}=0.96$.

One of the objectives of this work was to verify if the sooting behavior of a target fuel can be matched by a surrogate if the surrogate matches the fuel's carbon-type distribution. The surrogates developed for the CFA diesel fuel are useful to test this because the four surrogates studied in this work systematically increase in levels of compositional accuracy relative to the target fuel (i.e., the 4-component VOA matches CFA the worst, while the 9-component V2 matches CFA the best). From the YSI values in Table 3, it can be seen that, in general, the similarity in sooting tendency between the surrogates and the fuel increases with increased compositional similarity. The exception to this trend is VoB - it matches the sooting tendency of CFA the best (121 vs 122.2) even though it does not match its composition as well as the v1 or V2 surrogate. We hypothesize that this match is purely coincidental. In general there are many more ways to match the sooting tendency between a fuel and its surrogate without exactly matching the fuel's composition. For example, a binary mixture of $24 \%$ (by mass) 1-methylnaphthalene (YSI $=471.2)$ and $76 \% n$-hexadecane $(\mathrm{YSI}=11.7)$, as per YSI mixing rule (Eq 7a) in the following section, can be synthesized to match the YSI of CFA exactly, while not matching the carbon type distributions of the fuel (this binary mixture would have no cycloalkane-type carbon atoms, while $30 \%$ of the carbon atoms in CFA belong to this category [18]). Another example of this phenomenon is the HEX-12 surrogate developed by Eddings et al. [21], which matched the sooting tendency of its target (JP-8) fuel despite having very different carbon atom distributions, as determined through NMR measurements (see Table 2 in [17]). The results of this section and \$3.4.3 lend support to the hypothesis that developing surrogates for a fuel by matching the fuel's carbon-type distribution is sufficient but not necessary to match the fuel's sooting behavior. 
Based on the measured YSIs of these pure compounds, and the YSI contributions from the different carbon types in $\$ 3.4 .3$, we can predict the YSI of the surrogates in two ways,

$$
\begin{aligned}
\mathrm{YSI}_{\mathrm{SM}} & =\sum_{i=1}^{M} W_{i} \times \mathrm{YSI}_{\mathrm{PC}} \\
\mathrm{YSI}_{\mathrm{SM}} & =\sum_{i=1}^{M} W_{i} \times\left(\sum_{j=1}^{11} N_{j} \times \mathrm{C}_{j}\right)_{i}
\end{aligned}
$$

${ }_{446}$ where YSI $_{S M}$ is the predicted YSI of the surrogate mixture, $W_{i}$ is the mass fraction of compound $i$ in 447 each surrogate (listed in Tables 3 and 4 ), YSIPC is the measured YSI of the pure compound (listed in 448 Table 1$), M$ is the number of compounds in each surrogate, $N_{j}$ is the number of carbon atoms of type $449 j$ in compound $i$, and $\mathrm{C}_{j}$ is the contribution of each carbon type to the YSI (Table 5 ).

450 Figures 11 and 12 show comparisons between the experimentally measured YSIs of the fuel surro451 gates in Tables 3 and 4 ("Measured") and their predicted YSIs based on the component mixing rule ${ }_{452}$ (Eq 7a, "Predicted - A") and carbon-type mixing rule (Eq 7b, "Predicted - B"). It can be seen that we 453 can accurately predict the sooting tendency of the surrogates using either the measured YSI of their ${ }_{454}$ constituent compounds (4\% average error of prediction) or the YSI contributions from the various 455 carbon atom types present in the surrogate (5\% average error of prediction). This has two major 456 implications. First, the YSIs of the pure compounds in Table 1 can be used as design parameters in the 457 development of new fuel surrogates, as the sooting tendency of a surrogate composed of a mixture ${ }_{458}$ of these compounds can be predicted accurately using Eq 7a. Second, the relative accuracy of the 459 predicted YSIs using the carbon-type mixing rule $(\mathrm{Eq} 7 \mathrm{~b})$ makes it possible to expand the surrogate 460 palette beyond the compounds listed in Table 1. For instance, the YSI of one of the components of 461 diesel surrogate V2, 2-methylheptadecane, was not measured in this work. Although this precluded 462 using Eq 7a to predict the YSI of v2, all carbon atoms in 2-methylheptadecane were of either type CT1, 463 Ст2, or СТ3. Therefore, we could predict the YSI of the v2 surrogate using Eq $7 \mathrm{~b}$ to be $134 \pm 15$, which 464 compares very favorably to its measured YSI of $137.1 \pm 5$. 


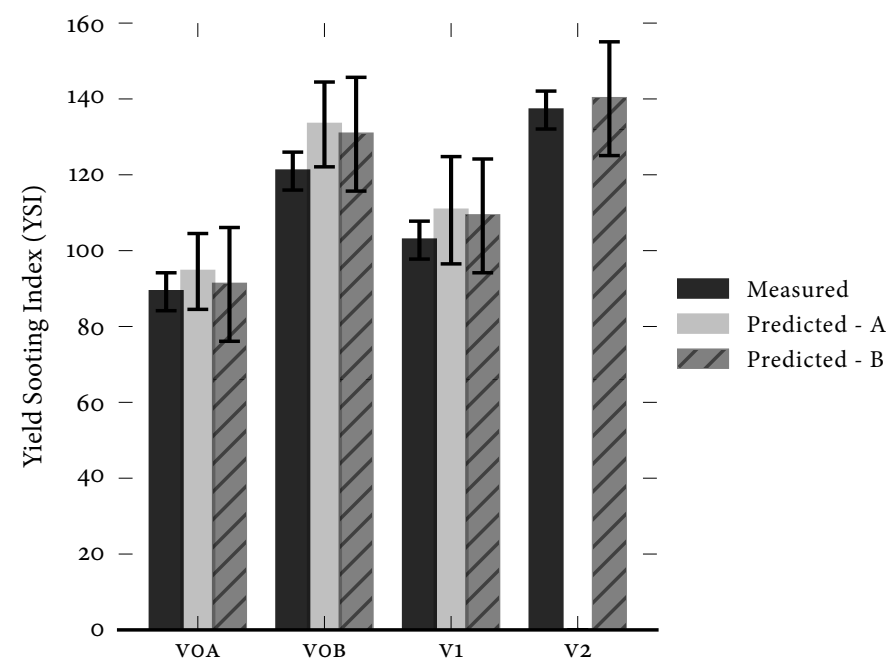

Figure 11: Comparison of measured and predicted sooting tendencies of some diesel surrogates.

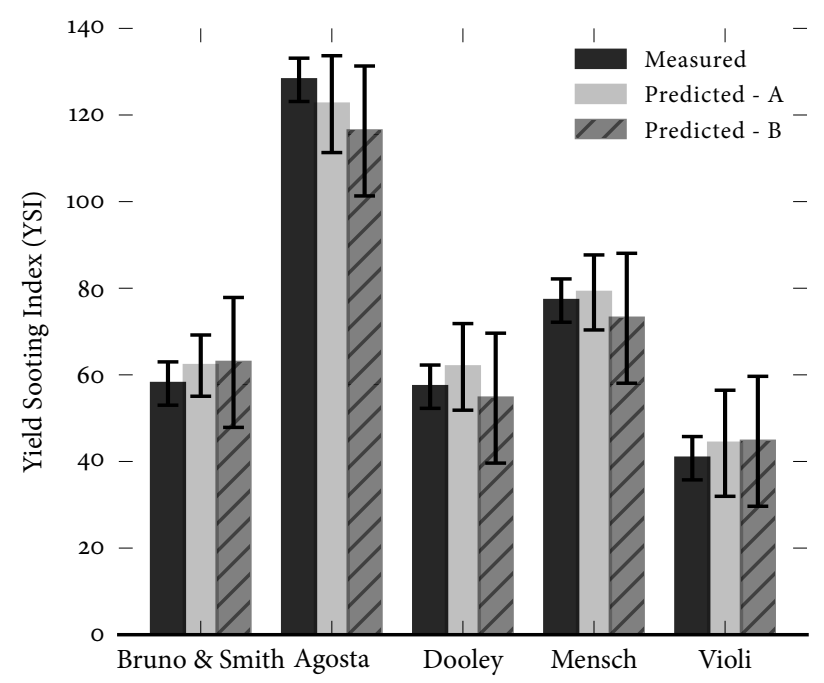

Figure 12: Comparison of measured and predicted sooting tendencies of some jet fuel surrogates.

465

466

467

468

469

\section{Conclusion}

In this work, we demonstrate the suitability of the doped-flame experimental method for comparing sooting tendencies of surrogates and their target diesel and jet fuels. We report these sooting tendencies 8 in terms of yield sooting indices (YSIs) for 2 diesel fuels, 4 jet fuels, 4 diesel fuel surrogates, 5 jet fuel surrogates, and 25 pure hydrocarbon compounds which are components of these surrogates. These 
YSIs are derived from full two-dimensional soot volume fraction maps for methane/air flames doped with these fuels and compounds. We observe a strong correlation between the sooting tendency and the relative abundance of different types of carbon atoms present in these fuels and compounds. We also demonstrate two approaches to predicting the YSI of a fuel surrogate, which can be used to tune the surrogate's formulation to match the sooting tendency of a target fuel. These results present the opportunity for developing new surrogates, composed of hydrocarbons with well-studied chemistry, which can be used to replicate the sooting behavior of most fuels.

\section{Acknowledgments}

We thank Avery Vella for assistance with conducting the experiments. We thank Dr. J. T. Edwards, Wright Patterson Air Force Base, for providing samples of jet fuels. This work was financially supported by NSF/US Department of Energy Partnership on Advanced Combustion Engines [grant number 1258654]. WJC's portion of the research was conducted at Chevron Energy Technology Co, Richmond, CA. CJM's portion of the research was conducted at the Combustion Research Facility, Sandia National Laboratories, Livermore, California. Sandia is a multi-program laboratory operated by Sandia Corporation, a Lockheed Martin Company, for the US Department of Energy's National Nuclear Security Administration under contract DE-ACO4-94AL8500o.

\section{References}

[1] World Health Organization, The World Health Report - 2002, http://www . who. int/whr/ 2002/en/whr02_en.pdf, (accessed Nov 2, 2016) (2002).

[2] T. W. Hesterberg, W. B. Bunn III, G. R. Chase, P. A. Valberg, T. J. Slavin, C. A. Lapin, G. A. Hart, A Critical Assessment of Studies on the Carcinogenic Potential of Diesel Exhaust, Critical Reviews in Toxicology 36 (9) (2006) 727-776. doi:10.1080/10408440600908821.

[3] C. Ris, U.S. EPA health assessment for diesel engine exhaust: a review., Inhalation Toxicology 19 Suppl 1 (2007) 229-239. doi:10.1080/08958370701497960.

[4] H.-E. Wichmann, Diesel Exhaust Particles, Inhalation Toxicology 19 (sup1) (2007) 241-244. doi:10.1080/08958370701498075.

[5] T. C. Bond, S. J. Doherty, D. W. Fahey, P. M. Forster, Others, Bounding the role of black carbon in the climate system: A scientific assessment, Journal of Geophysical Research: Atmospheres 118 (11) (2013) 5380-5552. doi:10.1002/jgrd.50171.

[6] T. W. Chan, E. Meloche, J. Kubsh, R. Brezny, Black carbon emissions in gasoline exhaust and a reduction alternative with a gasoline particulate filter, Environmental Science and Technology 48 (10) (2014) 6o27-6o34. doi: 10.1021/es501791b. 
[7] M. Z. Jacobson, Control of fossil-fuel particulate black carbon and organic matter, possibly the most effective method of slowing global warming, Journal of Geophysical Research Atmospheres 107 (19). doi : 10.1029/2001JD001376.

[8] C. J. Mueller, W. J. Cannella, J. T. Bays, T. J. Bruno, K. DeFabio, H. D. Dettman, R. M. Gieleciak, M. L. Huber, C.-B. Kweon, S. S. McConnell, W. J. Pitz, M. A. Ratcliff, Diesel Surrogate Fuels for Engine Testing and Chemical-Kinetic Modeling: Compositions and Properties, Energy \& Fuels 30 (2) (2016) 1445-1461. doi:10.1021/acs . energyfuels.5b02879.

[9] C. J. Mueller, W. J. Cannella, J. T. Bays, T. J. Bruno, K. DeFabio, H. D. Dettman, R. M. Gieleciak, M. L. Huber, C.-B. Kweon, S. S. McConnell, W. J. Pitz, M. A. Ratcliff, Correction to Diesel Surrogate Fuels for Engine Testing and Chemical-Kinetic Modeling: Compositions and Properties, Energy \& Fuels 30 (10) (2016) 8790-879o. doi:10.1021/acs . energyfuels.6b02499.

[10] W. J. Pitz, C. J. Mueller, Recent progress in the development of diesel surrogate fuels, Progress in Energy and Combustion Science 37 (3) (2011) 330-350. doi:10 .1016/j . pecs . 2010.06.004.

[11] M. E. Le Pera, The reality of the single-fuel concept., Army Logistician 37 (2) (2005) 41-43.

[12] P. Dagaut, M. Cathonnet, The ignition, oxidation, and combustion of kerosene: A review of experimental and kinetic modeling, Progress in Energy and Combustion Science 32 (1) (2006) 48-92. doi:10.1016/j.pecs.2005.10.003.

[13] M. Colket, T. Edwards, S. Williams, N. Cernansky, D. Miller, F. Egolfopoulos, P. Lindstedt, K. Seshadri, F. Dryer, E. Law, D. Friend, D. Lenhert, H. Pitsch, A. Sarofim, M. Smooke, W. Tsang, Development of an Experimental Database and Kinetic Models for Surrogate Jet Fuels, in: 45th AIAA Aerospace Sciences Meeting and Exhibit, Vol. 2007, American Institute of Aeronautics and Astronautics, Reston, Virigina, 2007, pp. 1-21. doi:10.2514/6.2007-770.

[14] J. T. Farrell, N. P. Cernansky, F. L. Dryer, C. K. Law, D. G. Friend, C. A. Hergart, R. M. McDavid, A. K. Patel, C. J. Mueller, H. Pitsch, Development of an Experimental Database and Kinetic Models for Surrogate Diesel Fuels, in: SAE Technical Paper, Vol. 2007-01-02, 2007. doi:10.4271/200701-0201.

[15] T. Edwards, L. Q. Maurice, Surrogate Mixtures to Represent Complex Aviation and Rocket Fuels, Journal of Propulsion and Power 17 (2) (2001) 461-466. doi : 10.2514/2 .5765.

[16] S. M. Sarathy, G. Kukkadapu, M. Mehl, W. Wang, T. Javed, S. Park, M. A. Oehlschlaeger, A. Farooq, W. J. Pitz, C. J. Sung, Ignition of alkane-rich FACE gasoline fuels and their surrogate mixtures, Proceedings of the Combustion Institute 35 (1) (2015) 249-257. doi:10.1016/j . proci. 2014. 05.122.

[17] H. R. Zhang, E. G. Eddings, A. F. Sarofin, C. L. Mayne, Z. Yang, R. J. Pugmire, Selection of surrogates for jet fuels, in: H. Bockhorn (Ed.), Combustion Generated Fine Carbonaceous 
Particles: Proceedings of an International Workshop Held in Villa Orlandi, Anacapri, May 13 - 16, 2007, KIT Scientific Publishing, 2009, Ch. 10, pp. 137-161. URL https: //books . google.com/books?id=8-Dk399oJwUC

[18] C. J. Mueller, W. J. Cannella, T. J. Bruno, B. Bunting, H. D. Dettman, J. A. Franz, M. L. Huber, M. Natarajan, W. J. Pitz, M. A. Ratcliff, K. Wright, Methodology for formulating diesel surrogate fuels with accurate compositional, ignition-quality, and volatility characteristics, Energy \& Fuels 26 (6) (2012) 3284-3303. doi:10.1021/ef300303e.

[19] C. J. Mueller, W. J. Cannella, J. T. Bays, T. J. Bruno, K. DeFabio, H. D. Dettman, R. M. Gieleciak, M. L. Huber, C.-B. Kweon, S. S. McConnell, W. J. Pitz, M. A. Ratcliff, Supporting Information for Diesel Surrogate Fuels for Engine Testing and Chemical-Kinetic Modeling: Compositions and Properties, Energy \& Fuelsdoi : 10.1021/acs .energyfuels. 5b02879.

[20] A. Violi, S. Yan, E. G. Eddings, A. F. Sarofim, S. Granata, T. Faravelli, E. Ranzi, Experimental formulation and kinetic model for JP-8 surrogate mixtures, Combustion Science and Technology 174 (11-12) (2002) 399-417. doi : 10 . 1080/00102200215080.

[21] E. G. Eddings, S. Yan, W. Ciro, A. F. Sarofim, Formulation of a Surrogate for the Simulation of Jet Fuel Pool Fires, Combustion Science and Technology 177 (4) (2005) 715-739. doi:10.1080/ 00102200590917248.

[22] R. Lemaire, A. Faccinetto, E. Therssen, M. Ziskind, C. Focsa, P. Desgroux, Experimental comparison of soot formation in turbulent flames of Diesel and surrogate Diesel fuels, Proceedings of the Combustion Institute 32 I (2009) 737-744. doi:10.1016/j . proci. 2008.05.019.

[23] A. Mensch, R. J. Santoro, T. a. Litzinger, S.-Y. Lee, Sooting characteristics of surrogates for jet fuels, Combustion and Flame 157 (6) (2010) 1097-1105. doi:10.1016/j . combustflame.2010.02 . 008.

[24] S. Dooley, S. H. Won, J. Heyne, T. I. Farouk, Y. Ju, F. L. Dryer, K. Kumar, X. Hui, C. J. Sung, H. Wang, M. A. Oehlschlaeger, V. Iyer, S. Iyer, T. A. Litzinger, R. J. Santoro, T. Malewicki, K. Brezinsky, The experimental evaluation of a methodology for surrogate fuel formulation to emulate gas phase combustion kinetic phenomena, Combustion and Flame 159 (4) (2012) 1444-1466. doi: $10.1016 / j$.combustflame.2011.11.002.

[25] D. Witkowski, K. Kondo, G. Vishwanathan, D. Rothamer, Evaluation of the sooting properties of real fuels and their commonly used surrogates in a laminar co-flow diffusion flame, Combustion and Flame 160 (6) (2013) 1129-1141. doi:10.1016/j .combustflame.2013.01.027.

[26] ASTM Standard D1322-15, Standard Test Method for Smoke Point of Kerosine and Aviation Turbine Fuel, ASTM International: West Conshohocken, PA, USA, 2011; DOI: http://dx . doi . org/10.1520/D1322 (2010). 
[27] C. S. McEnally, L. D. Pfefferle, Improved sooting tendency measurements for aromatic hydrocarbons and their implications for naphthalene formation pathways, Combustion and Flame 148 (4) (2007) 210-222. doi:10.1016/j.combustflame.2006.11.003.

[28] A. Hamins, D. T. Anderson, J. H. Miller, Mechanistic Studies of Toluene Destruction in Diffusion Flames, Combustion Science and Technology 71 (4-6) (1990) 175-195. doi:10.1080/ 00102209008951631.

[29] D. D. Das, C. S. McEnally, L. D. Pfefferle, Sooting tendencies of unsaturated esters in nonpremixed flames, Combustion and Flame 162 (4) (2015) 1489-1497. doi:10.1016/j.combustflame. 2014.11.012.

[30] M. Kashif, J. Bonnety, A. Matynia, P. Da Costa, G. Legros, Sooting propensities of some gasoline surrogate fuels: Combined effects of fuel blending and air vitiation, Combustion and Flame 162 (5) (2015) 1840-1847. doi:10.1016/j . combustflame.2014.12.005.

[31] Y. Xuan, G. Blanquart, Numerical modeling of sooting tendencies in a laminar co-flow diffusion flame, Combustion and Flame 16o (9) (2013) 1657-1666. doi:10.1016/j.combustflame. 2013.03 .034

[32] D. D. Das, W. J. Cannella, C. S. McEnally, C. J. Mueller, L. D. Pfefferle, Two-dimensional soot volume fraction measurements in flames doped with large hydrocarbons, Proceedings of the Combustion Institutedoi: 10.1016/j.proci.2016.06.047.

[33] CRC Fuels for Advanced Combustion Engines Working Group (FACE), https://crcao. org/publications/advancedVehiclesFuelsLubricants/FACE/, (accessed Nov 11, 2016) (2016).

[34] M. B. Colket, J. Heyne, M. Rumizen, J. T. Edwards, M. Gupta, W. M. Roquemore, J. P. Moder, J. M. Tishkoff, C. Li, An Overview of the National Jet Fuels Combustion Program, in: 54th AIAA Aerospace Sciences Meeting, no. January, American Institute of Aeronautics and Astronautics, Reston, Virginia, 2016, p. 0177. doi : 10.2514/6.2016-0177.

[35] A. Agosta, N. P. Cernansky, D. L. Miller, T. Faravelli, E. Ranzi, Reference components of jet fuels: Kinetic modeling and experimental results, Experimental Thermal and Fluid Science 28 (7) (2004) 701-708. doi:10.1016/j .expthermflusci.2003.12.006.

[36] T. J. Bruno, B. L. Smith, Evaluation of the physicochemical authenticity of aviation kerosene surrogate mixtures. Part 1: Analysis of volatility with the advanced distillation curve, Energy \& Fuels 24 (8) (2010) 4266-4276. doi:10.1021/ef100496j.

[37] C.S. McEnally, W.J. Cannella, D.D. Das, C.J. Mueller, J.D. Rockaway, A.J. Vella and L.D. Pfefferle, Sooting tendencies of surrogate diesel fuel mixtures, Combustion and Flame (in preparation). 
[38] H. Bufferand, L. Tosatto, B. La Mantia, M. D. Smooke, A. Gomez, Experimental and computational study of methane counterflow diffusion flames perturbed by trace amounts of either jet fuel or a 6-component surrogate under non-sooting conditions, Combustion and Flame 156 (8) (2009) 1594-1603. doi:10.1016/j.combustflame.2009.03.006.

[39] M. D. Smooke, R. J. Hall, M. B. Colket, J. Fielding, M. B. Long, C. S. McEnally, L. D. Pfefferle, Investigation of the transition from lightly sooting towards heavily sooting co-flow ethylene diffusion flames, Combustion Theory and Modelling 8 (3) (2004) 593-606. doi : 10.1088/1364$7830 / 8 / 3 / 009$.

[40] C. S. McEnally, L. D. Pfefferle, Sooting tendencies of oxygenated hydrocarbons in laboratoryscale flames., Environmental Science and Technology 45 (6) (2011) 2498-503. doi:10.1021/ es103733q.

[41] Design Institute for Physical Properties, Sponsored by AIChE, DIPPR Project 801 Full Version, http://app. knovel.com/hotlink/toc/id:kpDIPPRPF7/dippr-project801-full/dippr-project-801-full (2015).

[42] P. B. Kuhn, B. Ma, B. C. Connelly, M. D. Smooke, M. B. Long, Soot and thin-filament pyrometry using a color digital camera, Proceedings of the Combustion Institute 33 (1) (2011) 743-750. doi:10.1016/j.proci.2010.05.006.

[43] B. Ma, M. B. Long, Absolute light calibration using S-type thermocouples, Proceedings of the Combustion Institute 34 (2) (2013) 3531-3539. doi: 10.1016/j . proci.2012.05.030.

[44] H. Guo, J. A. Castillo, P. B. Sunderland, Digital camera measurements of soot temperature and soot volume fraction in axisymmetric flames, Applied Optics 52 (33) (2013) 8040. doi: 10.1364/AO.52.008040.

[45] D. R. Snelling, K. A. Thomson, G. J. Smallwood, O. L. Gulder, E. J. Weckman, R. A. Fraser, Spectrally Resolved Measurement of Flame Radiation to Determine Soot Temperature and Concentration, AIAA Journal 40 (9) (2002) 1789-1795. doi:10.2514/2.1855.

[46] P.A.M. Kalt and M.B. Long, OMA - Image processing for Mac OS X, http: //www . oma-x . org (2015).

[47] V. Dribinski, A. Ossadtchi, V. A. Mandelshtam, H. Reisler, Reconstruction of Abel-transformable images: The Gaussian basis-set expansion Abel transform method, Review of Scientific Instruments 73 (7) (2002) 2634. doi:10.1063/1.1482156.

[48] H. Calcote, D. Manos, Effect of molecular structure on incipient soot formation, Combustion and Flame 49 (1-3) (1983) 289-304. doi:10.1016/0010-2180 (83)90172-4. 
[49] D. Olson, J. Pickens, R. Gill, The effects of molecular structure on soot formation II. Diffusion flames, Combustion and Flame 62 (1) (1985) 43-6o. doi : 10.1016/0010-2180 (85) 90092-6.

[50] R. Martel, Charles, C. Angello, Leonard, Hydrogen Content As a Measure of the Combustion Performance of Hydrocarbon Fuels, Tech. Rep. May, Air Force Aero Propulsion Laboratory, Wright-Patterson Air Force Base, OH (1973).

[51] Ö. L. Gülder, B. Glavinčevski, M. F. Baksh, Fuel Molecular Structure and Flame Temperature Effects on Soot Formation in Gas Turbine Combustors., ASME 1989 International Gas Turbine and Aeroengine Congress and Expositiondoi:10.1115/89-GT-288.

[52] K. Nakakita, K. Akihama, W. Weissman, J. T. Farrell, Effect of the hydrocarbon molecular structure in diesel fuel on the in-cylinder soot formation and exhaust emissions, International Journal of Engine Research 6 (3) (2005) 187-205. doi: 10.1243/146808705X7400.

[53] M. Frenklach, Reaction mechanism of soot formation in flames, Physical Chemistry Chemical Physics 4 (11) (2002) 2028-2037. doi:10.1039/b110045a.

[54] M. P. Hanson, D. H. Rouvray, Novel applications of topological indices. 2. Prediction of the threshold soot index for hydrocarbon fuels, The Journal of Physical Chemistry 91 (11) (1987) 2981-2985. doi: 10.1021/j100295a067.

[55] K. Aikawa, T. Sakurai, J. J. Jetter, Development of a Predictive Model for Gasoline Vehicle Particulate Matter Emissions, SAE International Journal of Fuels and Lubricants 3 (2) (2010) 610-622. doi: 10.4271/2010-01-2115.

[56] Ö. L. Gülder, B. Glavinčevski, S. Das, Effect of Molecular Structure on Soot Formation Characteristics of Aviation Turbine Fuels, Journal of Engineering for Gas Turbines and Power 111 (1) (1989) 77. doi:10.1115/1.3240230.

[57] Ö. L. Gülder, Influence of hydrocarbon fuel structural constitution and flame temperature on soot formation in laminar diffusion flames, Combustion and Flame 78 (2) (1989) 179-194. doi:10.1016/0010-2180(89)90124-7.

[58] D. J. Cookson, B. E. Smith, Calculation of Jet and Diesel Fuel Properties Using 13C NMR Spectroscopy, Energy \& Fuels 4 (6) (1990) 152-156. doi : 10.1021/ef00020a004.

[59] R. Meusinger, R. Moros, Determination of octane numbers of gasoline compounds from their chemical structure by ${ }_{13} \mathrm{C}$ NMR spectroscopy and neural networks, Fuel 80 (5) (2001) 613-621. doi:10.1016/S0016-2361(00)00125-3.

[6o] G. S. Kapur, A. Ecker, R. Meusinger, Establishing quantitative structure-property relationships (QSPR) of diesel samples by proton-NMR \& multiple linear regression (MLR) analysis, Energy \& Fuels 15 (4) (2001) 943-948. doi : 10.1021/ef010021u. 
[61] Y. Yang, A. L. Boehman, R. J. Santoro, A study of jet fuel sooting tendency using the threshold sooting index (TSI) model, Combustion and Flame 149 (1-2) (2007) 191-205. doi : 10.1016/j . combustflame.2006.11.007.

[62] A. G. Abdul Jameel, N. Naser, A.-H. Emwas, S. Dooley, S. M. Sarathy, Predicting Fuel Ignition Quality Using 1H NMR Spectroscopy and Multiple Linear Regression, Energy \& Fuels (2016) acs.energyfuels.6bo169odoi:10 .1021/acs . energyfuels.6b01690.

[63] S. W. Benson, J. H. Buss, Additivity Rules for the Estimation of Molecular Properties. Thermodynamic Properties, The Journal of Chemical Physics 29 (3) (1958) 546. doi : 10.1063/1.1744539.

[64] S. Yan, E. G. Eddings, A. B. Palotas, R. J. Pugmire, A. F. Sarofim, Prediction of Sooting Tendency for Hydrocarbon Liquids in Diffusion Flames, Energy \& Fuels 19 (6) (2005) 2408-2415. doi: 10.1021/ef050107d.

[65] P. Pepiot-Desjardins, H. Pitsch, R. Malhotra, S. R. Kirby, A. Boehman, Structural group analysis for soot reduction tendency of oxygenated fuels, Combustion and Flame 154 (1-2) (2008) 191-205. doi:10.1016/j.combustflame.2008.03.017.

[66] A. R. Katritzky, M. Kuanar, S. Slavov, C. D. Hall, M. Karelson, I. Kahn, D. A. Dobchev, Quantitative correlation of physical and chemical properties with chemical structure: Utility for prediction, Chemical Reviews 110 (2010) 5714-5789. doi:10.1021/cr900238d.

[67] S. Dooley, S. H. Won, M. Chaos, J. Heyne, Y. Ju, F. L. Dryer, K. Kumar, C. J. Sung, H. Wang, M. A. Oehlschlaeger, R. J. Santoro, T. A. Litzinger, A jet fuel surrogate formulated by real fuel properties, Combustion and Flame 157 (12) (2010) 2333-2339. doi:10.1016/j . combustflame.2010 .07. 001.

[68] T. Edwards, Personal Communication with Charles McEnally (2016).

[69] ASTM Standard D1319-15, Standard test method for hydrocarbon types in liquid petroleum products by fluorescent indicator adsorption, ASTM International: West Conshohocken, PA, USA, 2011; DOI: http://dx .doi.org/10.1520/D1319-15 (2015).

[70] ASTM Standard D5186-150, Standard Test Method for Determination of the Aromatic Content and Polynuclear Aromatic Content of Diesel Fuels and Aviation Turbine Fuels, ASTM International: West Conshohocken, PA, USA, 2015; DOI: http://dx .doi .org/10.1520/D518603R09. 2 (2015).

[71] California Air Resources Board, The California Diesel Fuel Regulations, https : //www . arb .ca. gov/fuels/diesel/081404dslregs.pdf, (accessed Nov 2, 2016) (2004).

[72] R. Gieleciak, C. Fairbridge, Detailed Hydrocarbon Analysis of FACE Diesel Fuels Using Comprehensive Two-Dimensional Gas Chromatography, Tech. Rep. October, Coordinating Research 


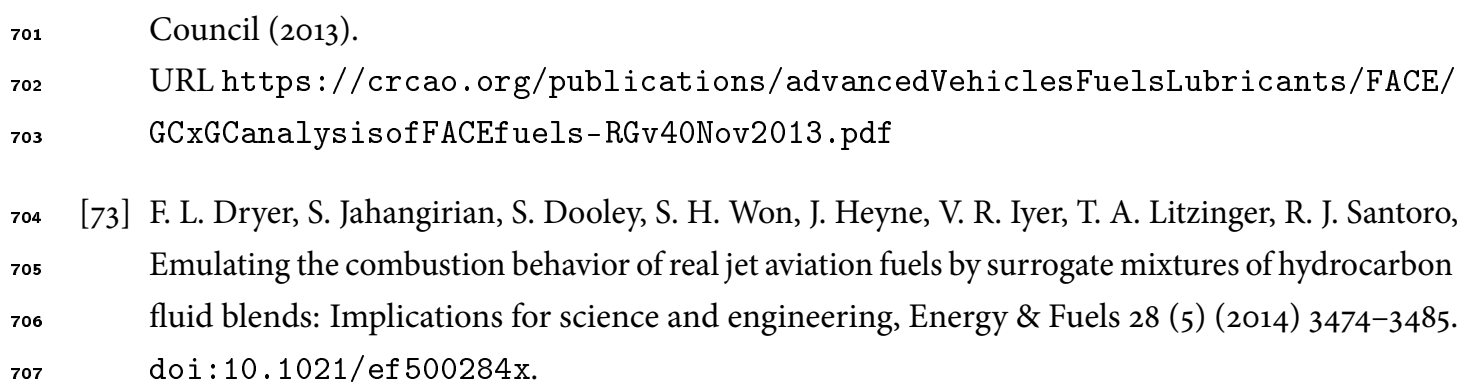

